\title{
Highlights of Coastal Waves 1996
}

\author{
David P. Rogers, ${ }^{*}$ Clive E. Dorman, ${ }^{*}$ Kathleen A. Edwards, ${ }^{*}$ Ian M. Brooks, ${ }^{*}$ \\ W. Kendall Melville, ${ }^{*}$ Stephen D. Burk, ${ }^{+}$William T. Thompson, ${ }^{+}$Teddy Holt, ${ }^{+}$ \\ Linda M. Ström," Michael Tjernström," Branko Grisogono,", John M. Bane, ${ }^{@}$ \\ Wendell A. Nuss, ${ }^{\&}$ Bruce M. Morley, ${ }^{* *}$ and Allen J. Schanot ${ }^{* *}$
}

\begin{abstract}
Some of the highlights of an experiment designed to study coastal atmospheric phenomena along the California coast (Coastal Waves 1996 experiment) are described. This study was designed to address several problems, including the cross-shore variability and turbulent structure of the marine boundary layer, the influence of the coast on the development of the marine layer and clouds, the ageostrophy of the flow, the dynamics of trapped events, the parameterization of surface fluxes, and the supercriticality of the marine layer.

Based in Monterey, California, the National Center for Atmospheric Research (NCAR) C-130 Hercules and the University of North Carolina Piper Seneca obtained a comprehensive set of measurements on the structure of the marine layer. The study focused on the effects of prominent topographic features on the wind. Downstream of capes and points, narrow bands of high winds are frequently encountered. The NCAR-designed Scanning Aerosol Backscatter Lidar (SABL) provided a unique opportunity to connect changes in the depth of the boundary layer with specific features in the dynamics of the flow field.

An integral part of the experiment was the use of numerical models as forecast and diagnostic tools. The Naval Research Laboratory's Coupled Ocean Atmosphere Model System (COAMPS) provided high-resolution forecasts of the wind field in the vicinity of capes and points, which aided the deployment of the aircraft. Subsequently, this model and the MIUU (University of Uppsala) numerical model were used to support the analysis of the field data.

These are some of the most comprehensive measurements of the topographically forced marine layer that have been collected. SABL proved to be an exceptionally useful tool to resolve the small-scale structure of the boundary layer and, combined with in situ turbulence measurements, provides new insight into the structure of the marine atmosphere. Measurements were made sufficiently far offshore to distinguish between the coastal and open ocean effects. COAMPS proved to be an excellent forecast tool and both it and the MIUU model are integral parts of the ongoing analysis. The results highlight the large spatial variability that occurs directly in response to topographic effects. Routine measurements are insufficient to resolve this variability. Numerical weather prediction model boundary conditions cannot properly define the forecast system and often underestimate the wind speed and surface wave conditions in the nearshore region.

This study was a collaborative effort between the National Science Foundation, the Office of Naval Research, the Naval Research Laboratory, and the National Oceanographic and Atmospheric Administration.
\end{abstract}

* Scripps Institution of Oceanography, La Jolla, California.

${ }^{+}$Naval Research Laboratory, Monterey, California.

\#Department of Meteorology, Uppsala University, Uppsala, Sweden.

${ }^{\circledR}$ University of North Carolina, Chapel Hill, North Carolina.

\&Naval Postgraduate School, Monterey, California.

**Research Aviation Facility, National Center for Atmospheric Research, Boulder, Colorado.

Corresponding author address: Dr. David P. Rogers, Physical Oceanography Research Division, Scripps Institution of Oceanography, University of California, San Diego, La Jolla, CA 92093 0230 .

In final form 6 February 1998.

(C)1998 American Meteorological Society

\section{Introduction}

The Coastal Waves 1996 experiment (CW96), which took place in June 1996, was designed to investigate the structure of the coastal marine atmospheric boundary layer in summer conditions. Despite the importance of the coastal zone, there have been relatively few observational studies designed to quantify the processes that control the spatial variability of the coastal marine atmosphere. The California coastal atmosphere is modified by the coastal moun- 
tain ranges, whose influence may extend more than $100 \mathrm{~km}$ offshore (Overland 1984). Measurements of the coastal atmosphere were obtained between the shoreline and the open ocean, from southern Oregon to the Santa Barbara Channel, and from 30 to several thousand meters above sea level. The observing systems included the National Center for Atmospheric Research (NCAR) C-130 Hercules aircraft; an instrumented, light twin-engine aircraft operated by the University of North Carolina; and several instrumented surface sites along the coast. The C-130 has the range and endurance to provide extensive surveys of the coastal boundary later and the capability of combining in situ and remote sensing measurements. The smaller aircraft provides a set of basic measurements at low cost and with a rapid-response deployment.

The coastal topography along the west coast of the United States generally exceeds $400 \mathrm{~m}$, forming an almost continuous barrier to the marine atmosphere from southern California to Oregon. The marine boundary layer depth is typically below the height of the terrain, and thus the flow tends to follow the coastline. Irregularities in the topography affect the depth of the boundary layer and the velocity of the wind. These orographically induced flows have a significant effect on the exchange of heat, moisture, momentum, and trace constituents between the ocean and the atmosphere. Since these flows are constrained by the topography they are often stationary and persistent, tied to specific geographical features such as points and capes.

Here we describe some of the highlights of the experiment. Abrupt changes in wind speed, boundary layer depth, sea surface temperature, and other parameters occurred frequently in the vicinity of capes and points, associated with abrupt changes in the coastline. By combining aerosol backscatter lidar and in situ turbulence measurements, we were able to observe the connection between mixing forced by processes at the marine layer inversion with the surface fields. We were also able to demonstrate the importance and utility of mesoscale forecast models, which were an integral part of the experiment planning and resource deployment.

This was a collaborative field experiment, involving several institutions, supported by the National Science Foundation, the Office of Naval Research, the Naval Research Laboratory, and the National Oceanographic and Atmospheric Administration.

\section{Previous results and theoretical considerations}

The present study was motivated by earlier experiments, such as the Coastal Ocean Dynamics Experiment, (CODE; Beardsley et al. 1987); the Shelf Mixed Layer Experiment, (SMILE; Dorman and Winant 1995); and the Monterey Area Ship Tracks Experiment, (MAST; Brooks and Rogers 1997). These prompted a closer investigation of the topographic forcing of the marine boundary layer that focused on a range of time and space scales. There have been numerous experiments conducted off the California coast, but investigations of topographic forcing have been limited to a few cases.

Along the California coast, the marine boundary layer is frequently very shallow and capped by a large temperature inversion (Neiberger et al. 1961). The marine boundary layer has a typical depth of 300$400 \mathrm{~m}$ but may be as low as $30 \mathrm{~m}$ and as high as $800 \mathrm{~m}$ (Beardsley et al. 1987). The typical potential air temperature difference across the inversion is $10^{\circ} \mathrm{C}$, which means that the cool, moist marine air is about $1 / 30$ denser than the warm, dry air immediately above.

The dense marine layer moving under a less dense upper layer is separated by a well-defined density interface, which can support gravity waves. The speed of a long gravity wave in the layer is given by

$$
C_{\mathrm{g}}=\sqrt{g h\left(\frac{\theta_{\mathrm{u}}-\theta_{1}}{\theta_{1}}\right)},
$$

where $g$ is the acceleration of gravity, $h$ is the depth of the layer, $\theta_{1}$ is the potential temperature of the lower layer, and $\theta_{\mathrm{u}}$ is the potential temperature of the upper layer (Winant et al. 1988). In practice, $\theta_{\mathrm{u}}$ is the potential temperature at the top of the air temperature inversion and $h$ is the mean of the heights of the air temperature inversion base and top. Dynamical complications arise if the speed of the layer is faster than the inherent wave speed. The formal expression of this is the Froude number Fr, which is the ratio of the wind speed, $U$, to the long gravity wave speed, or $\mathrm{Fr}=U / C_{\mathrm{g}}$. If Fr is greater than 1, then the flow is supercritical and long waves may not progress upstream.

Supercritical marine layer flow along coastal mountains offers the opportunity for another dynamical feature, the expansion fan. The expansion fan occurs as supercritical flow passes around a point or a cape when 
the coastline bends away from the flow. In response the layer accelerates and thins (Winant et al. 1988). Aircraft measurements in 1981 and 1982 showed that there was supercritical flow and an expansion fan in the marine layer around Point Arena, California.

Air over the cool coastal ocean is frequently stable. In stable conditions, mechanical turbulence is suppressed by a downward heat flux. Consequently, the layer in which turbulence can be maintained is typically an order of magnitude shallower than that under unstable conditions (Holtslag and Nieuwstadt 1986). The structure of the stable boundary layer differs from the unstable boundary layer because of the predominance of small eddies. The interaction of gravity waves and turbulence adds a further complication. A completely satisfactory similarity theory has not been developed, although there have been some advances. A local similarity theory, developed by Nieuwstadt (1984) and Sorbjan (1986) over land, relates nondimensional fields to the local velocity, temperature, and height scales, rather than surface scaling. Rogers et al. (1995a,b) applied a similar approach to the stable coastal marine layer with some success. Universal application has not been possible, however, due to the lack of appropriate comprehensive measurements. The interaction of the stable marine layer with the coastal mountains gives rise to a number of important effects along the coast. These include lowlevel jets (LLJ) with associated hydraulic flows and large spatial variations in the surface wind stress and wind stress curl (e.g., Zemba and Friehe 1987).

Burk and Thompson (1996) conducted mesoscale model simulations of the marine boundary layer structure typical of summer conditions. They proposed explanations for the LLJ dynamics, which encompass its intensity, diurnal variation, and interaction with orography, and they speculate upon implications for coupling with the upwelling coastal ocean. One aspect of the study involves the interaction of the supercritical flow within the marine boundary layer with the orography of Cape Mendocino. The marine layer flow shows first-order effects of an expansion in the lee of Cape Mendocino. There may be modifications of this model by air flowing over the cape topography and descending in over the thinned marine layer in the lee, further lowering the surface pressure and contributing to the surface wind accelerations.

Although the winds in the California coastal marine layer are mostly northerly (Nelson 1977), wind reversals can occur (Dorman and Winant 1995). These are associated with coastally trapped disturbances that develop as Kelvin waves, gravity currents, or both (Dorman 1985, 1987; reviewed in Reason 1989; Reason and Steyn 1990). These disturbances can have a significant impact on the cloud cover, the strength and direction of the wind stress, and oceanic upwelling.

\section{Coastal Waves 1996}

\section{a. Motivation}

CW96 was designed to address several areas of coastal meteorology, including

- the cross-shore variability of the marine boundary layer;

- the turbulent structure of the marine boundary layer;

- the influence of the coastal mountains and thermal gradients on the development of the marine layer and coastal clouds;

- the alongshore and cross-shore ageostrophy of the mean flow forced by the adjacent barrier;

- the dynamics of coastally trapped events, such as Kelvin waves and density currents;

- the parameterization of surface fluxes in stable conditions; and

- the supercriticality of the marine boundary layer.

\section{b. Field experiment}

To resolve the topographic forcing of the coastal atmosphere, it was necessary to capture all of the important time and space scales. The dominant horizontal scale is the Rossby radius of deformation, which is a measure of the offshore distance influenced by the coastal mountains (Overland 1984). The influence of the coastline extends more than $100 \mathrm{~km}$ offshore with substantial variations in structure as the atmosphere responds to changes in the height and shape of the coastline. The important vertical scale is the depth of the boundary layer, which is generally shallow near the coast and deeper offshore. Aircraft measurements can resolve the spatial variability with flight tracks designed to obtain information both within the region influenced by the coast and the unperturbed open ocean region. These measurements were restricted to the daytime. Resolving the diurnal and longer variations in the marine layer requires surface-based, continuous measurements. Time series need to be sufficiently long to capture the rarer coastally trapped disturbances, which occur about twice a month during the summer (Bond et al. 1996). Many of these 
longer-term measurements composed the Experiment on Coastally Trapped Disturbances (ECTD), which was the field experiment of the Office of Naval Research (ONR) sponsored Coastal Meteorology Accelerated Research Initiative (ARI). The results from the ECTD field effort and associated model studies will be described in a subsequent paper in the Bulletin of the American Meteorological Society.

Mesoscale numerical weather prediction models were a critical element of the experimental phase of the study. The Naval Research Laboratory (NRL) Coupled Ocean-Atmosphere Mesoscale Prediction System (COAMPS) was run in real time in support of the aircraft operations to help define the observational domain and sampling strategy.

\section{c. Instrumentation}

1) NCAR C-130 STANDARD SENSORS

The primary measurement platform in CW96 was the NCAR C-130 Hercules aircraft (Fig. 1), recently acquired by NCAR to support atmospheric and oceanographic research. The long range $[>1800 \mathrm{n} \mathrm{mi}$ $(3200 \mathrm{~km})]$ and endurance $(>9 \mathrm{~h})$ of this aircraft make it ideal for offshore measurements, while its large payload capacity provides the opportunity to collocate a large array of complementary sensors on one platform. The standard instrument suite includes duplicate sensors for many parameters to assure data quality. High-frequency wind, temperature, and humidity measurements are provided to the user at $25 \mathrm{~Hz}$. The wind data were derived from the radome wind gust package, which includes an inertial reference and GPS positioning system. The dataset includes measurements made with three standard temperature sensors. The reference temperature used is the standard unheated Rosemount sensor. Humidity measurements were made using two collocated thermoelectric dewpoint sensors and two Lyman-alpha fast-response hygrometers. The latter are subject to in-flight drift in the

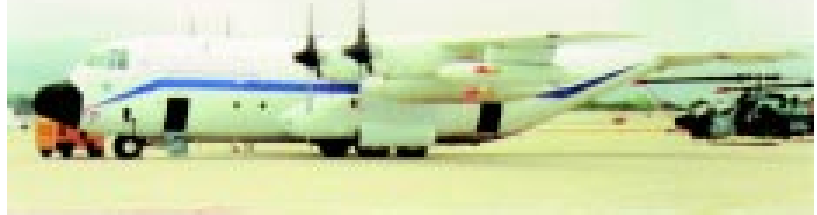

FIG. 1. NCAR C-130 Hercules aircraft on the ramp at Monterey airport, June 1996. instrument's bias voltage. This drift is compensated by referencing the Lyman alpha to one of the more stable thermoelectric dewpointers. Accurate sea surface skin temperatures are difficult to obtain. Two Heinmann radiometers provided radiometric measurements of the surface brightness temperature in the range $9.6-11.5 \mu \mathrm{m}$. The sea surface temperature is obtained by correcting these data for sky reflectance using the upward-looking Epply pyrgeometer.

2) SCANning Aerosol backscatter LidAR (SABL)

Airborne remote sensing of the boundary layer structure was a goal of CW96. An innovation at NCAR is the dual-wavelength Scanning Aerosol Backscatter Lidar (SABL) developed by the Atmospheric Technology Division (ATD) of NCAR (Fig. 2). The specifications of the lidar are summarized in Table 1 . The conceptual design for the SABL transmitter and receiver module was completed at NCAR. The optical and mechanical design and construction of the SABL telescope and receiver were completed by Lentec Corporation of Albuquerque, New Mexico. The telescope is a 14-in. Cassegrainian with a speed of $f / 5$. The critical components of the telescope are built of lowexpansion materials so that the optical performance is temperature insensitive. The receiver is built on an optical plate rigidly mounted to the telescope base to minimize the effects of vibration.

Operated in nadir- or zenith-pointing mode from a location in the main cabin of the $\mathrm{C}-130$, SABL pro-

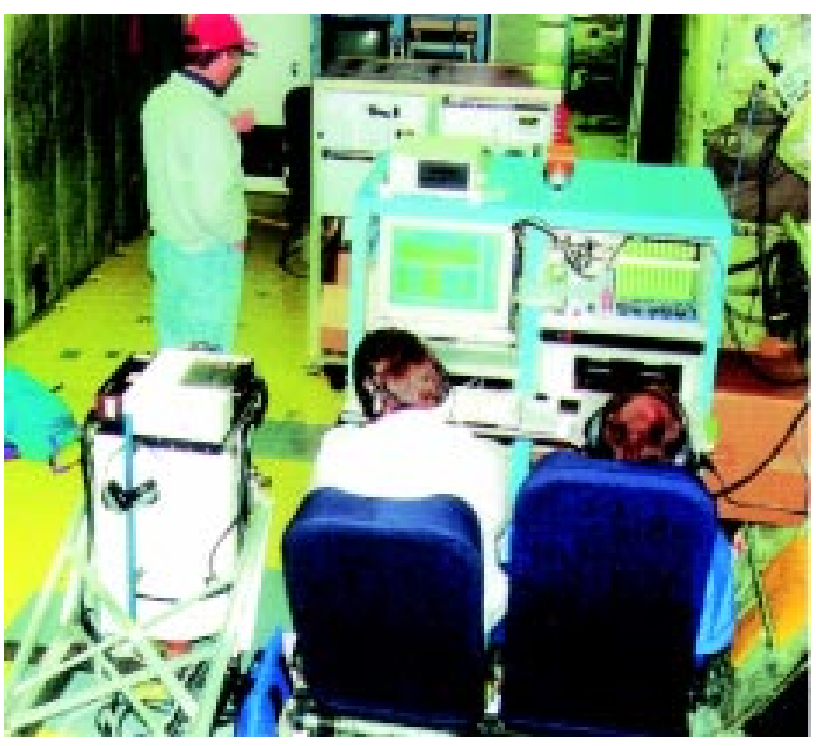

FIG. 2. NCAR-SABL deployed on C-130 in nadir-pointing mode. The lidar can be manually switched between nadir and zenith pointing. 
vides a nearly instantaneous picture of the atmosphere. In addition to boundary layer height, SABL can distinguish multiple layers identified by distinct aerosol composition or concentration and features of the circulation of the boundary layer. Air mixed into the boundary layer at the inversion can have a low aerosol content compared with air originating near the sea surface. Simultaneous turbulence and aerosol backscatter measurements can be used to study exchange processes between the boundary layer and the free atmosphere, the relationship between the surface layer and cloud development, and the structure at the top of the boundary layer.

\section{3) UNC LIGHT TWIN-ENGINE AIRCRAFT SENSORS}

Sampling rare and highly intermittent events, such as atmospheric coastally trapped wind reversals requires a sampling strategy that is both capable of tracking events and available for long periods. A Piper Seneca III aircraft (Fig. 3), operated by the University on North Carolina (UNC), was equipped to obtain atmospheric wind, temperature, humidity, and pressure measurements to resolve the main features of these elusive events.

This aircraft is an all-metal, low wing, nonpressurized, twin-engine platform capable of carrying six persons, including the pilot. It is powered by

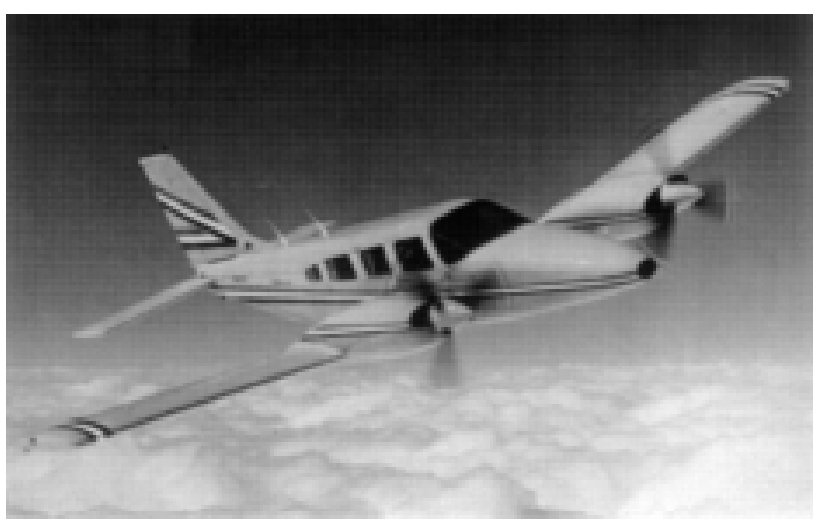

FIG. 3. Piper Seneca III instrumented and operated by UNC at Chapel Hill.

TABLE 1. NCAR Scanning Aerosol Backscatter Lidar components.

\section{Device/parameter}

Wavelength/energy

Pulselength

Beam divergence

Telescope diameter/speed

Telescope field of view

Background filter bandwidths

Detectors

Digitizer-two channels

Number of range gates per

channel

Recording media

Transmitter/receiver size

Transmitter/receiver weight

Computer/operating system

Rack space

\section{Unit}

1064 nm/75 mJ; 532 nm/50 mJ

$15 \mathrm{~ns}$

1-4 mrad (adjustable)

14 in./1 f.

1-5 mrad (adjustable)

$092 \mathrm{~nm}$ at $1064 \mathrm{~nm} ; 0.16 \mathrm{~nm}$ at $532 \mathrm{~nm}$

Avalanche photo diode at $1064 \mathrm{~nm}$ Photomultiplier tube at $532 \mathrm{~nm}$

12 bits at up to $40 \mathrm{MHz}$

Up to 2500

Exabyte tape

$15 \times 15 \times 32$ in.

110 lbs; VME Bus/VxWorks for data acquisition

Sun Sparc-5 for display and control $<48$ in. of 19-in. rack

22 in. deep two Continental, turbocharged, 220-horsepower, piston engines, and it can cruise at altitudes up to $25000 \mathrm{ft}$ (7625 m) above sea level. Typical flight speeds range from about $90 \mathrm{kt}\left(46 \mathrm{~m} \mathrm{~s}^{-1}\right)$ true airspeed during climbs, to a maximum of $190 \mathrm{kt}\left(98 \mathrm{~m} \mathrm{~s}^{-1}\right)$ true airspeed in cruise. Typical cruise configuration is $165 \mathrm{kt}\left(85 \mathrm{~m} \mathrm{~s}^{-1}\right)$ true airspeed at an altitude of about $10000 \mathrm{ft}(3050 \mathrm{~m})$. For typical flights, the absolute endurance of the aircraft is just under $6 \mathrm{~h}$, and its maximum range is about 950 nautical miles $(1760 \mathrm{~km})$.

Air temperature is measured with a Rosemount Model 102E4AL total temperature sensor. Relative humidity is measured with a Vaisala Model 504 capacitance humidity sensor. A Vaisala Model PTA427A barometer measures static pressure, and a Setra Model 239 differential pressure sensor measures the aircraft's indicated airspeed. A KVH Model C100 flux-gate compass measures the aircraft's heading, and 
a Garmin Model 150 GPS receiver is used for the aircraft's horizontal position (latitude and longitude), ground speed, and ground track. Absolute altitude above the sea surface is obtained with a Terra Model TRA 3500 radar altimeter. A complete description of the aircraft, its systems, and its sensors is provided by Bane et al. (1995).

\section{4) Surface MEASUREMENTS}

To keep track of the sea level temporal variations, a network of automated meteorological stations were deployed by the Scripps Institution of Oceanography (SIO) along the coast (Fig. 4). These measured 1-min averages of the surface winds, temperature, and humidity. Additional SIO stations were on oil platforms in the Santa Barbara Channel-Point Conception area. The

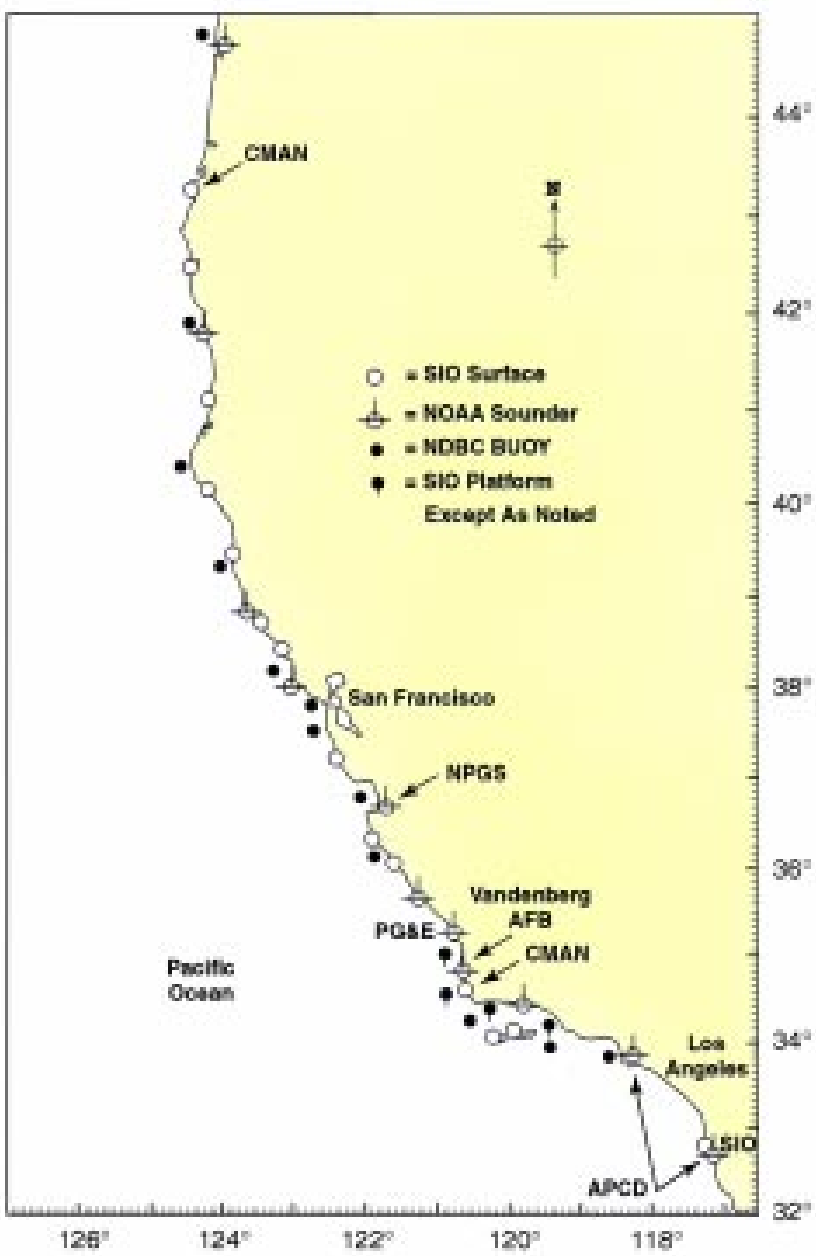

FIG. 4. West Coast surface meteorological stations and radar profilers. Automated surface stations are maintained and operated by SIO unless otherwise noted. Radar profilers are maintained and operated by NRL NOAA unless otherwise noted. NDBC buoy locations are also shown. Oil platform automated surface stations around Point Conception are operated by SIO.
Naval Postgraduate School (NPS) maintained stations at Point Sur and Fort Ord. These measurements complemented the hourly averaged surface data from National Data Buoy Center (NDBC) buoys (typically about $20 \mathrm{~km}$ offshore) and three land-based CMAN stations.

The temporal variations in the lower atmosphere were tracked by a network of National Oceanic and Atmospheric Administration WPL radar profilers. These stations stretch from the central Oregon coast to Santa Barbara (Fig. 4); all of the stations included automated surface measurements and some included acoustical sounders. The NPS maintained a radar profiler at Fort Ord. The air pollution control districts of South Coast and of San Diego operated radar profilers at the coast in Los Angeles and San Diego, respectively. Acoustical sounders were run by Vandenberg AFB at Vandenberg and by the Pacific Gas and Electric Company at Diablo Canyon. Completing the West Coast upper-air network were conventional, twice-aday, balloon soundings at the NWS stations in San Diego, Oakland, Medford, and the USAF station at Vandenberg.

To help refine our understanding of the synopticscale forcing of coastally trapped disturbances and other coastal weather events, the NPS collected a variety of special observations. The two primary observational efforts were to conduct additional rawinsonde soundings at several sites and to deploy drifting buoys along the coast. Special soundings were made on a daily basis at Point Sur to the south of Monterey to define the day-to-day variability in the marine layer structure. Special 6-h soundings were made at Beale Air Force Base, Le Moore Naval Air Station, and Fort Hunter-Liggett during intensive observation periods aimed at examining the initiation and evolution of coastally trapped disturbances. Drifting buoys were deployed in late May and again in mid-June off the Oregon coast. These drifting buoys measured atmospheric pressure, surface air temperature, sea surface temperature, and drift current obtained from sequential positions determined by Service ARGOS. The buoys stored and transmitted hourly measurements of the atmospheric pressure and temperature, which were used to supplement the routine hourly ship and coastal moored buoy observations.

\section{d. Operations}

1) Airborne missions

The project was based at the Naval Postgraduate School in Monterey, California. The COAMPS synoptic and mesoscale forecasts guided the planning of 
each aircraft mission. The mesoscale prediction of strong, or weak, wind forcing in a particular geographical location largely determined the aircraft operations. Northwesterly winds forced the largest coastal response, while southerly flow was indicative of the onset of a coastally trapped event.

While each flight focused on a different aspect of the boundary layer response to the topography, similar patterns were flown. Horizontal tracks were flown parallel and perpendicular to the coast. The length of the track was governed by the need to resolve the boundary layer structure between the undisturbed, open ocean conditions and the coast and the downstream response of the boundary layer to a particular cape or point. Space-height cross sections are obtained from a series of "sawtooth" profiles. These are flown between a minimum altitude of $30 \mathrm{~m}$ and a typical maximum altitude of $1000 \mathrm{~m}$, at a rate of ascent of approximately $5 \mathrm{~m} \mathrm{~s}^{-1}$. Upper and lower boundaries are obtained from horizontal runs at 30 and $1000 \mathrm{~m}$. Time permitting, additional horizontal runs were obtained above $30 \mathrm{~m}$ to derive flux divergences.

The C-130 Hercules flew 11 missions between Cape Blanco and the Santa Barbara Channel in southern California (Fig. 5a). The C-130 Hercules missions focused on three geographical locations: Cape Mendocino to Cape Blanco, Point Sur, and Point Con-

(a)

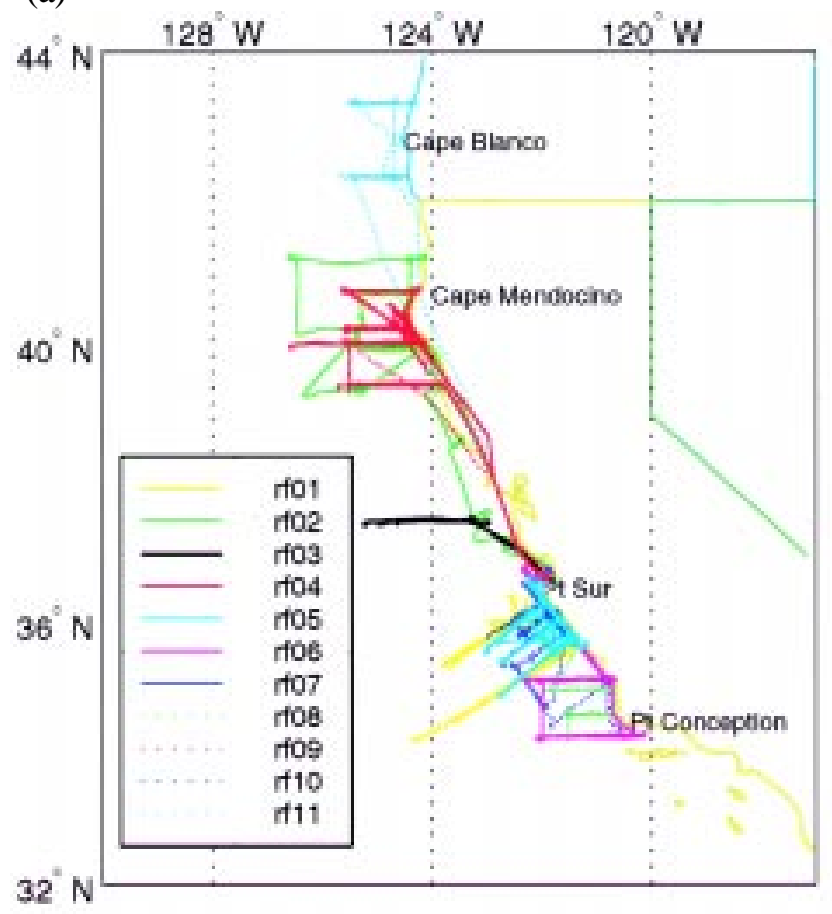

ception. Table 2 summarizes the $\mathrm{C}-130$ Hercules flights.

The Piper Seneca flew 10 missions during June 1996 between Cape Blanco and the Santa Barbara Channel (Fig. 5b) while participating in CW96. One coastally trapped wind reversal was observed, and flights were made near Point Piedras Blancas and in the Santa Barbara Channel to investigate the interaction of supercritical northerly wind flow with coastal topography. Additional flights were flown by this aircraft in 1994 (7 flights) and 1996 (23 flights) in pursuit of coastally trapped wind reversals as part of the ONR-sponsored ECTD. Results from these flights, together with other observations and numerical simulations on these events, will be the subject of a later paper in the Bulletin of the American Meteorological Society.

\section{2) COAMPS SUPPORT}

COAMPS is designed to predict atmospheric phenomena as small as meso- $\beta$ scale $(2-10 \mathrm{~km})$ for flow that is externally forced by interactions with the lower boundary surface (see Hodur 1997 for a detailed system description). The system comprises two components that can be used in a coupled or stand-alone mode. The first is an atmospheric data assimilation component featuring data quality control, analysis, initialization, and a nonhydrostatic numerical model. The second is an ocean-modeling component featuring a hydrostatic ocean model. The nonhydrostatic

(b)

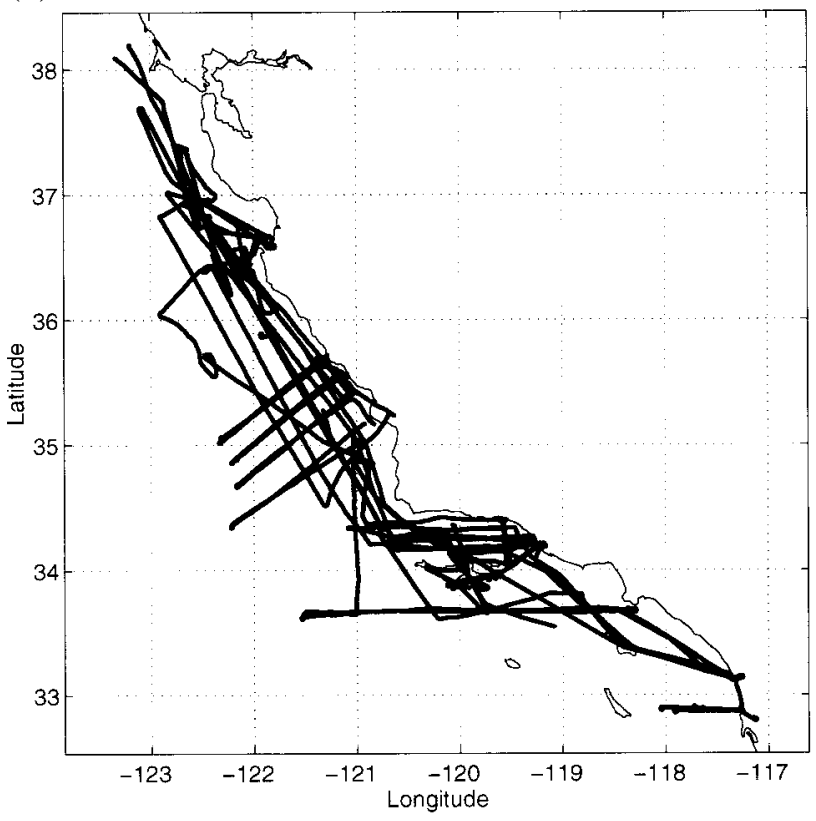

FIG. 5. Maps showing flight tracks of (a) C-130 Hercules and (b) Piper Seneca III. 


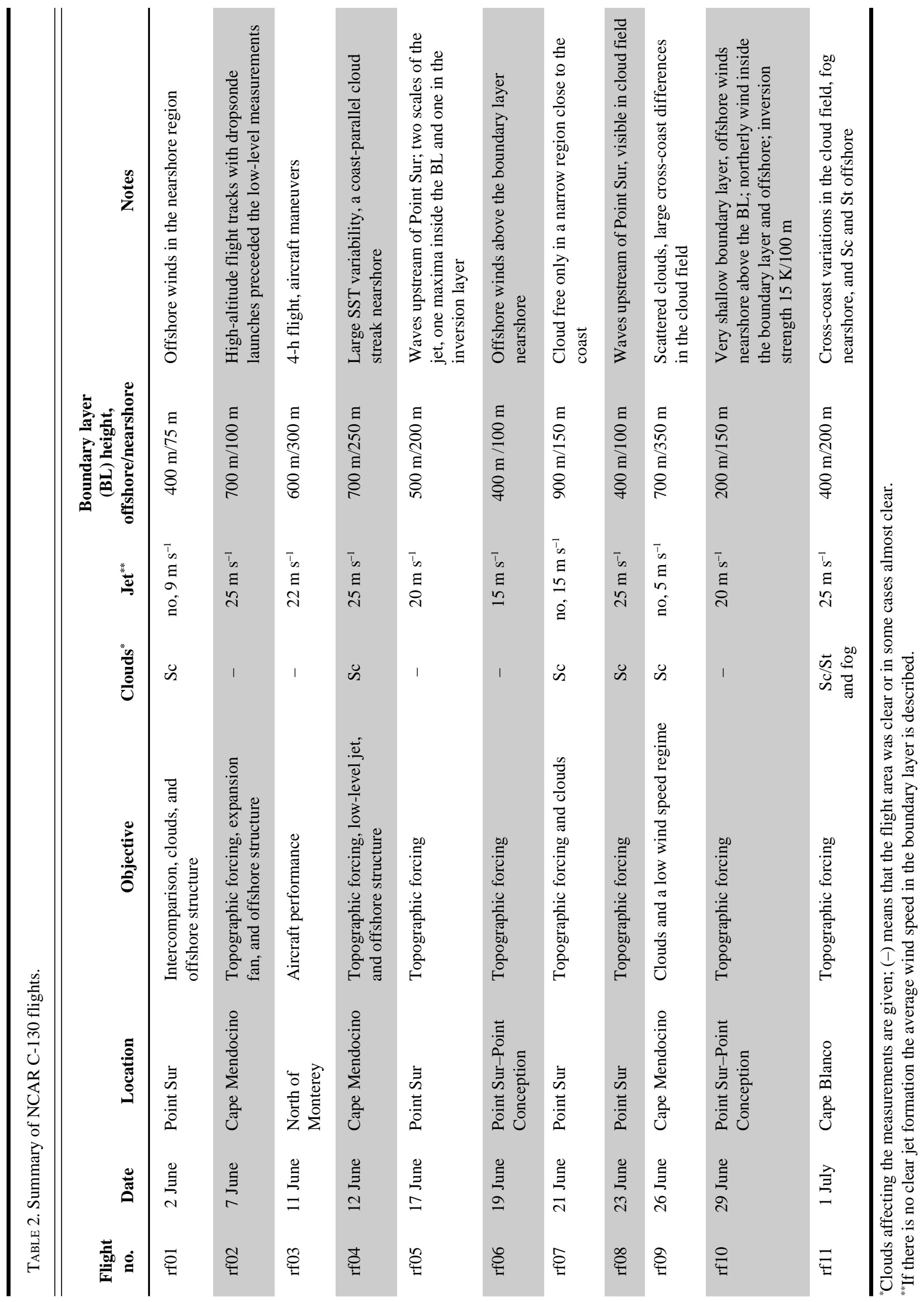


numerical model used in the atmospheric data assimilation component of COAMPS solves the fully compressible equations of motion (Klemp and Wilhelmson 1978). The dynamics package includes parameterizations for subgrid-scale mixing (Mellor and Yamada 1982), explicit moist physics (Rutledge and Hobbs 1983), cumulus convection (Kain and Fritsch 1993), radiation (Harshvardhan et al. 1987), and surface fluxes (Louis et al. 1982).

The simulations performed in support of CW96 were run using the atmospheric data assimilation component only. COAMPS was run using computational resources at the Fleet Numerical Meteorology and Oceanography Center (FNMOC). The system was run in a 12-h intermittent data assimilation mode using the analysis-forecast cycle technique, producing 36-h forecasts every $12 \mathrm{~h}$ on a triply nested domain centered on the California coast. Initial and boundary condition data (every $6 \mathrm{~h}$ ) were provided from the Navy Operational Global Atmospheric Prediction System (NOGAPS). The sea surface temperature (SST) is obtained from a bilinear interpolation of the $1^{\circ}$ FNMOC global SST analysis and is held constant for a 24-h forecast. Model terrain is obtained from either the U.S. Navy 20' resolution terrain database or the Defense Mapping Agency (DMA) Digital Terrain Elevation Data (DTED) level 1 database (100-m resolution).

\section{Observations}

\section{a. Spatial fields}

A direct influence of the coast is the acceleration and expansion of winds in the nearshore region. A typical example of the wind, SST, and buoyancy flux fields, measured at 30-m altitude, is shown in Fig. 6. The nearshore local wind maximum (Fig. 6a) has a large impact on the shelf water. Northerly winds drive surface water offshore, which is compensated by upwelling of colder water (Fig. 6b). The SST varies from a minimum close to, and south of, Cape Mendocino in this example. Farther offshore, beyond the influence of the coast, the SST increases to typical open ocean values. The colder sea surface temperature cools the air above, forming a stable layer with a negative buoyancy flux (Fig. 6c). The buoyancy flux map calculated from a series of 30-m level runs indicates that the boundary layer is most stably stratified in a narrow northsouth band close to the coast, which coincides with the coldest SST. Away from the influence of the coast, the
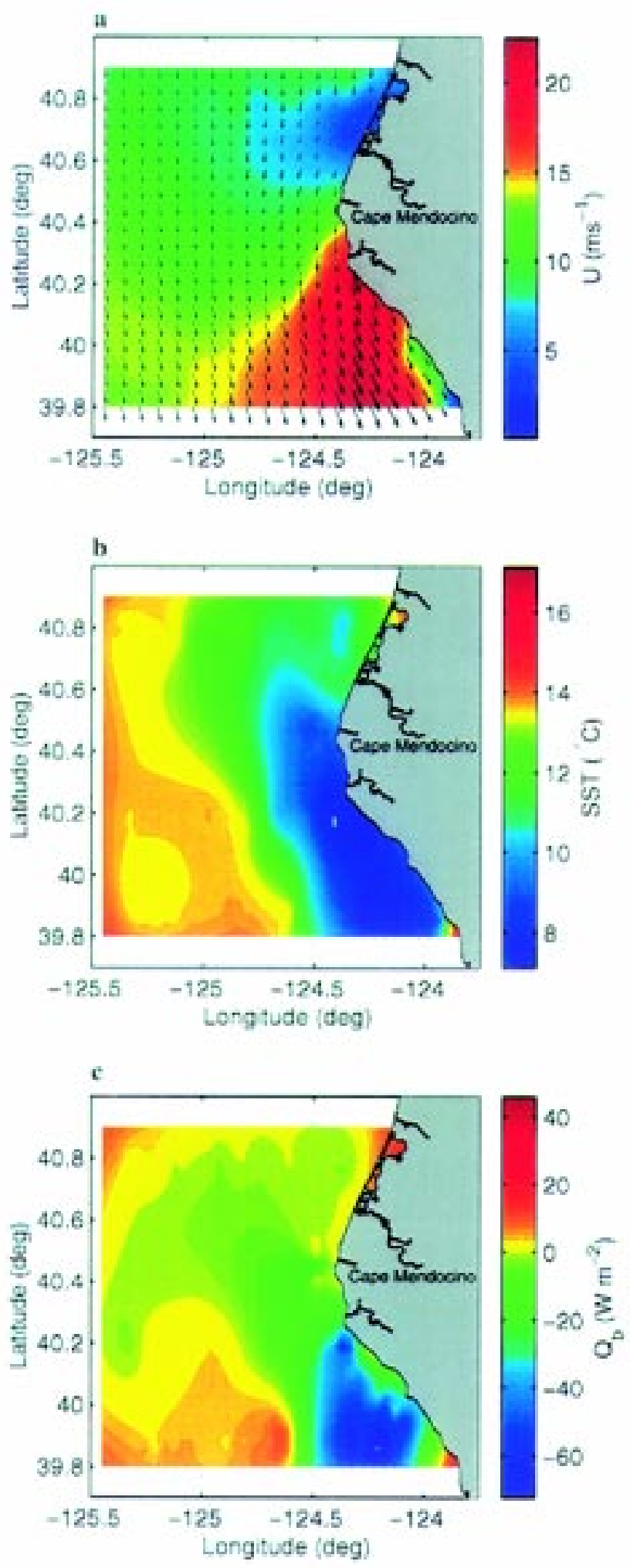

FIG. 6. Examples of (a) wind, (b) SST, and (c) buoyancy flux fields calculated from aircraft data at $30 \mathrm{~m}$. 
air is in radiative equilibrium with the surface conditions resulting in a slightly unstable boundary layer.

\section{b. Horizontal and vertical structure}

The aerosol backscatter lidar is a useful tool to determine the vertical structure of the boundary layer. Previous in situ, near-surface turbulence measurements have revealed much about the structure of the marine atmosphere. However, it is often difficult to relate measurements near the surface with processes originating at the top of the boundary layer, for example, cloud radiative forcing, shear-driven mixing, and entrainment instability. By combining the in situ measurements with the SABL data, we have the opportunity to resolve the influence of remote forcing on the surface layer and interpret near-surface measurements in the context of the overall boundary layer structure.

\section{1) Alongshore}

The alongshore variation in the structure of the marine layer derived from SABL and the corresponding 30-m horizontal wind speed, observed in the vicinity of Point Sur, is shown in Fig. 7. The variation of the backscatter intensity is a good indicator of the depth of the boundary layer. The figure shows several important features. Close to Point Sur $\left(36^{\circ} 18^{\prime} \mathrm{N}\right.$, $\left.121^{\circ} 51^{\prime} \mathrm{W}\right)$, gravity waves modulate the depth of the boundary on a horizontal scale of $1 \mathrm{~km}$. As the air moves south of the point, there is a rapid decrease in the depth of the marine layer from about 500 to $150 \mathrm{~m}$ and a corresponding increase in the wind speed. Farther south, the boundary layer deepens again and the wind speed decreases.

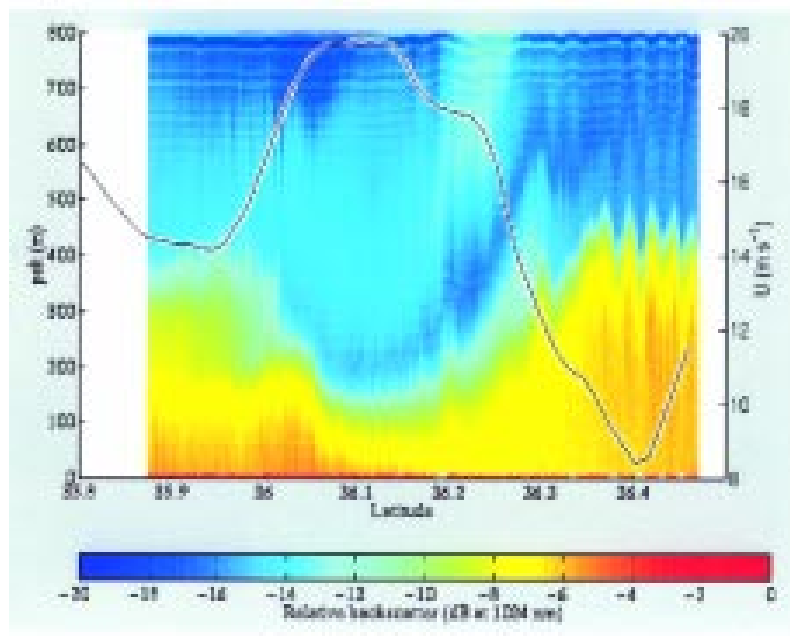

FIG. 7. SABL and 30-m wind speed superimposed for 17 June 1996.

\section{2) Across SHORE}

Typical cross sections, obtained perpendicular to the coast near Cape Mendocino on 7 and 12 June, are shown in Fig. 8. These demonstrate the large spatial variation in the vertical structure associated with the increasing dynamical influence of the topography and the change in SST as the coastline is approached. Figure 8a shows the potential temperature cross section and relative humidity on 7 June. The depth of the boundary decreases from about $600 \mathrm{~m}$ offshore $(0 \mathrm{~km}$ alongtrack) to less than $50 \mathrm{~m}$ close to the coast (>100 km alongtrack) with an average temperature discontinuity at the inversion of $10^{\circ} \mathrm{C}$. The relative humidity indicates that the boundary layer is everywhere close to saturation or saturated with a rapid decrease to less than $30 \% \mathrm{RH}$ above the inversion. The influence on the coast on the wind field is apparent. Offshore the flow is northerly and apparently unaffected by the coast. Within $60 \mathrm{~km}$ of the shore, the steering effect of the topography is obvious with the wind backing to parallel the coast. A wind speed jet is observed approximately $20 \mathrm{~km}$ offshore with the maximum wind speed coincident with the temperature inversion at the top of the marine layer. There is a large velocity gradient to the east of the jet with wind speeds decreasing from near 30 to $2 \mathrm{~m} \mathrm{~s}^{-1}$. Essentially the same conditions prevail on 12 June. The track is longer, but the main features occur in about the same geographical location as 7 June.

The SABL measurements obtained along the 1000-m track, corresponding to the 12 June section, are shown in Fig. 9. The lidar shows the organization of the boundary with regions of high backscatter return corresponding to cloud cover, separated by low backscatter return corresponding to gaps in the cloud layer. The organization of this structure is indicative of a secondary circulation often associated with boundary layer rolls (e.g., Brooks and Rogers 1997). The wind speed measured at $30 \mathrm{~m}$ is superimposed on this track. This shows clearly the correspondence between the wind maximum and the minimum boundary layer depth.

\section{c. Turbulent fluxes}

The development and refinement of parameterizations of the turbulent surface fluxes of heat, moisture, and momentum in stable boundary layers is an important component of coastal marine atmospheric and oceanographic research.

As a first step, CW96 observations of eddy correlation fluxes can be compared with bulk fluxes parameterized using one of the more recent schemes (Fairall 

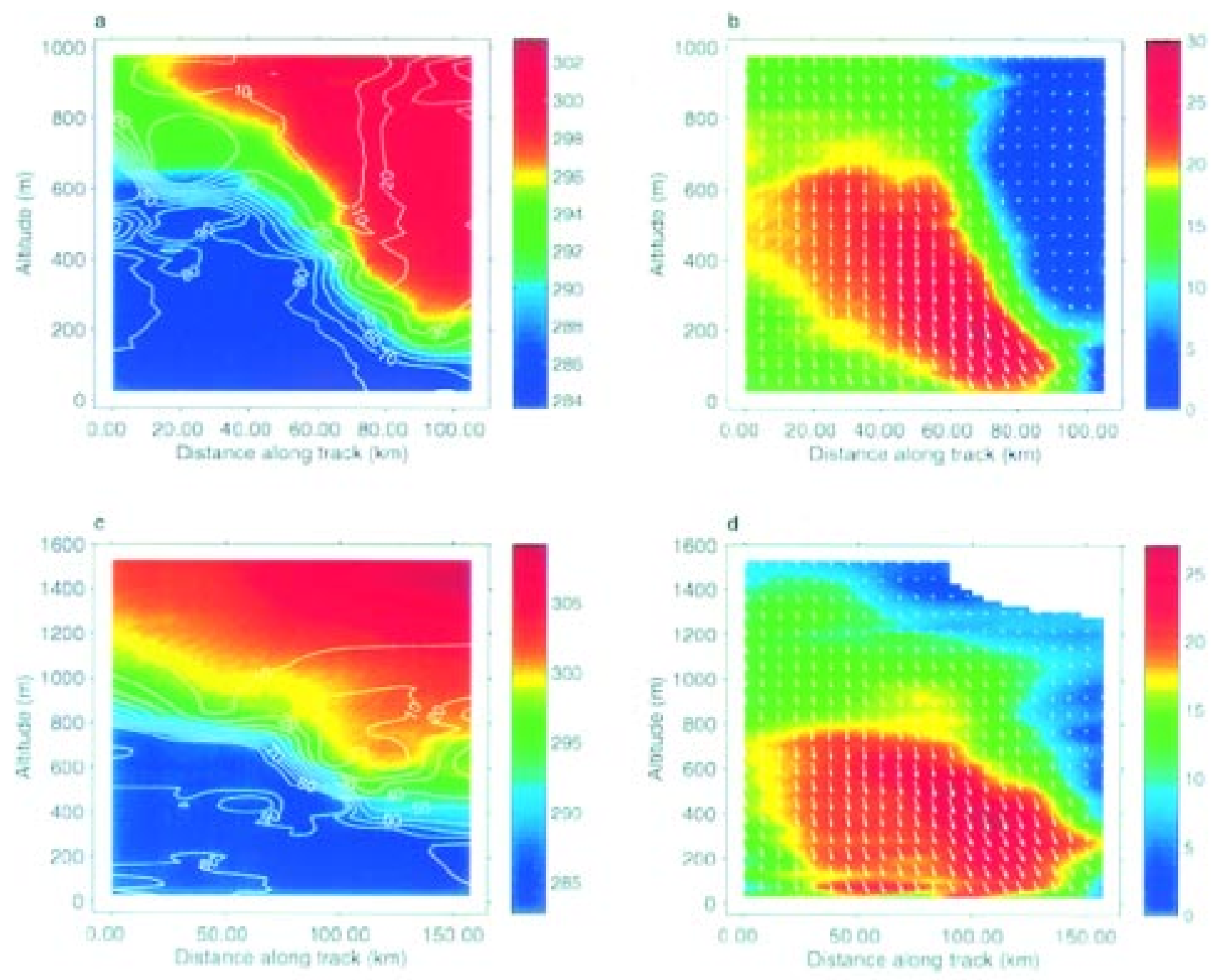

FIG. 8. Cross sections of (a) p-RH, (b) wind speed and direction for 7 June, (c) p-RH, and (d) wind speed and direction for 12 June.

et al. 1996). The differences highlight some of the problems with existing parameterizations. The stable parameterizations are essentially derived from measurements over land and lack verification over the ocean. Figure 10 shows eddy correlation and bulk fluxes grouped by dynamic stability. The few unstable values agree well. However, large differences are observed in the stable regime. Here the eddy latent heat flux indicates condensation at the sea surface and the eddy correlation wind stress is small despite the high wind speeds. Figure 11 shows the variation of the fluxes along a single track. The cause of these large variations is not yet certain; however, uncertainty in the form of the nondimensional heat, moisture, and momentum profiles is likely to be important.

\section{d. Supercritical flow}

Froude numbers for selected high speed wind days

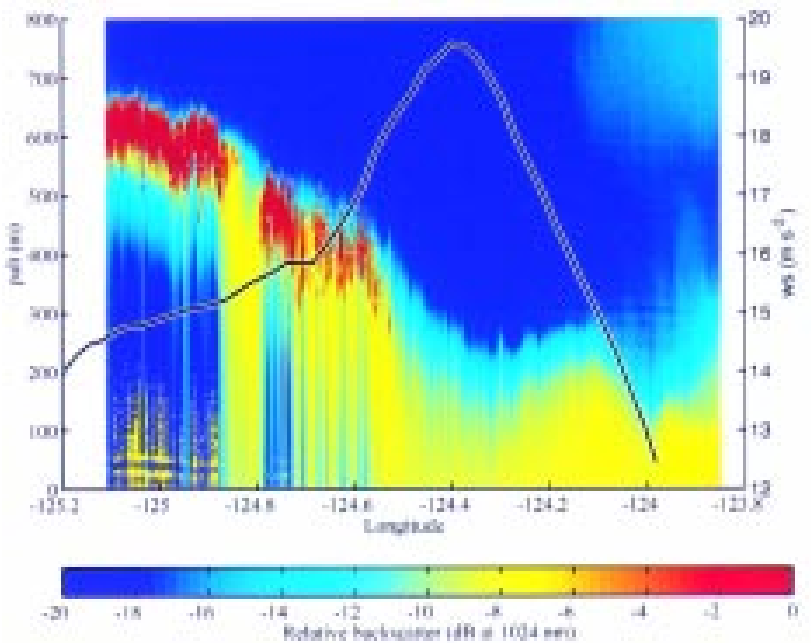

FIG. 9. SABL image obtained from flight track perpendicular to the coast on 12 June 1996. 

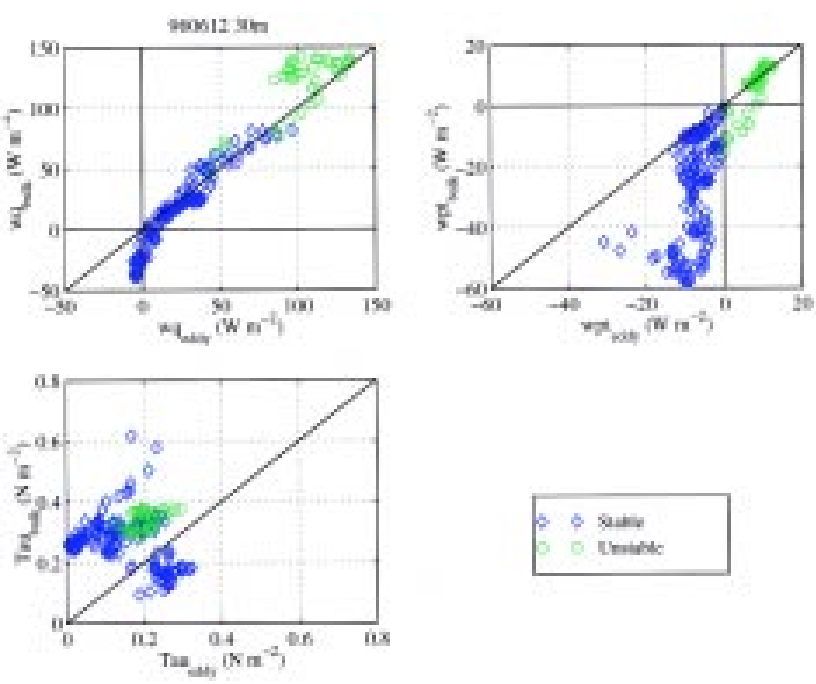

FIG. 10. Eddy correlation and bulk fluxes as a function of stability ( $z / L$, where $L$ is the Monin-Obukhov length scale). The boundary layer is neutral in the range $-0.01<z / L<0.01$ ) for 12 June.
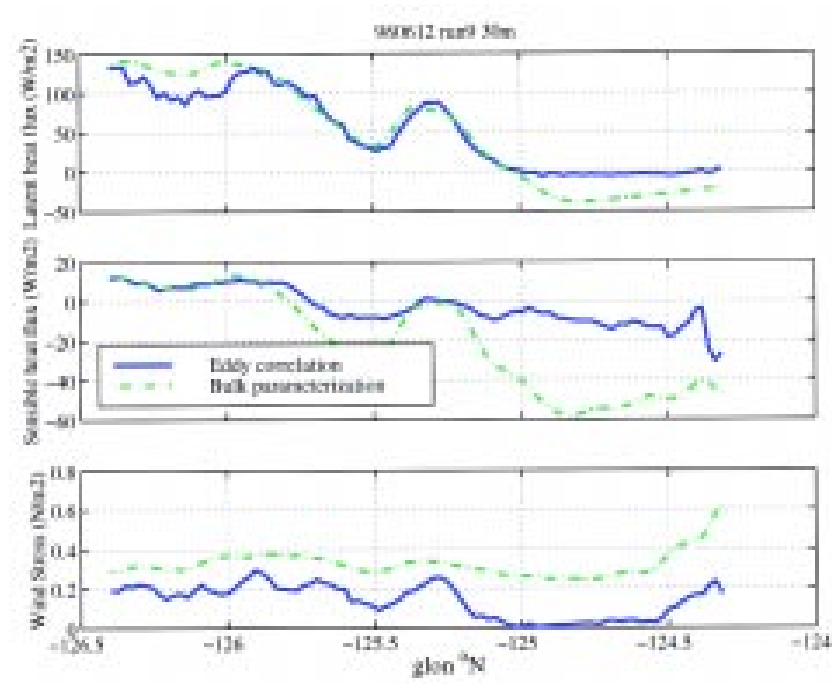

FIG. 11. Variations in the fluxes along a single 30 -m track on 12 June.
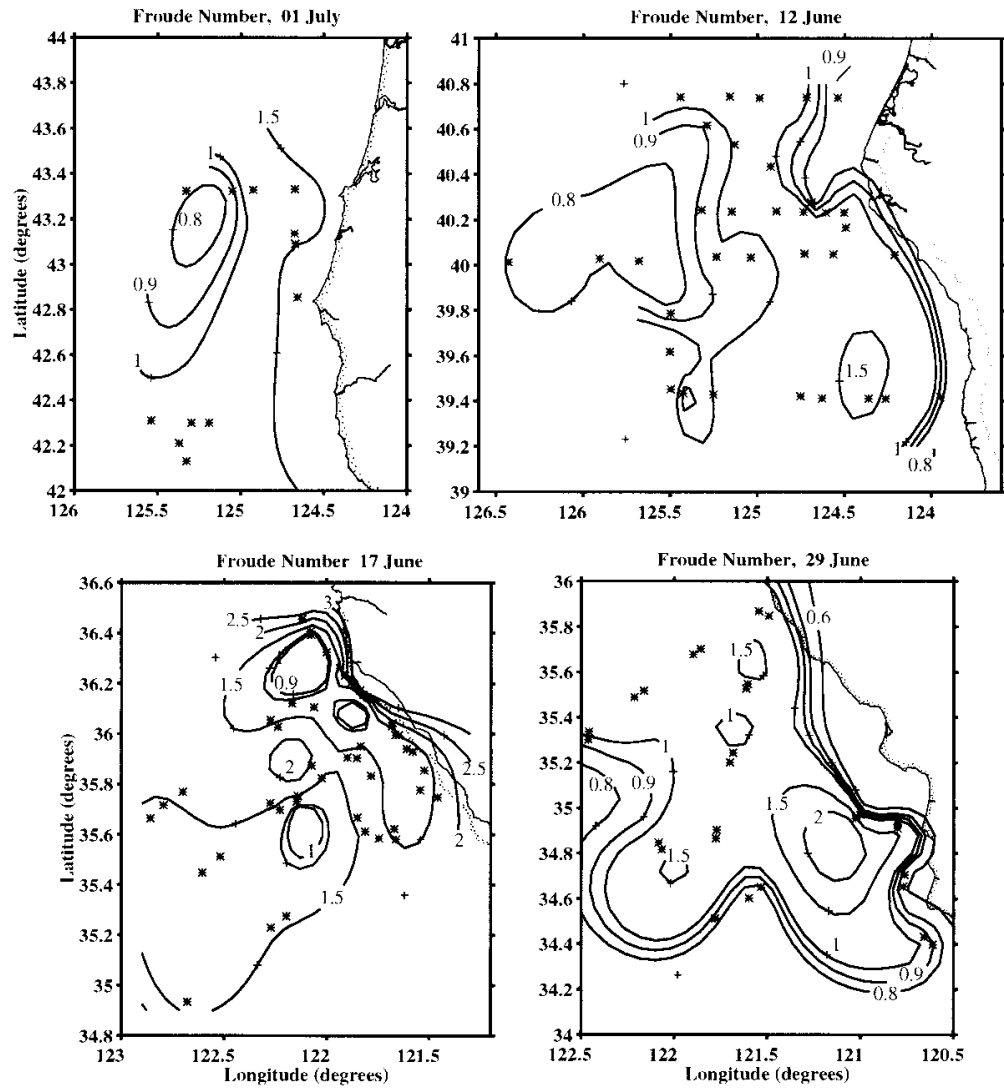

FIG. 12. Froude numbers of the marine layer along the Oregon-California coast. Data were taken by the C-130 at Cape Blanco on 1 July, Cape Mendocino on 12 June, Point Sur on 17 June, and Point Arguello on 29 June. The UNC Piper Seneca took the 17 June data on either side of the Channel Islands in the Southern California Bight. are shown in Fig. 12. The Froude number exceeded 1 in the inner $60 \mathrm{~km}$ at Cape Blanco and at Cape Mendocino with maximums near 1.5. Farther to the south at Point Sur, the supercritical zone expanded to beyond $120 \mathrm{~km}$ and the highest values exceeded 2. At Point Conception, the supercritical zone extended to about $110 \mathrm{~km}$ offshore and the highest value was less than 1.7. It was supercritical north of the Channel Islands in the Santa Barbara Channel and subcritical to the south.

The inversion height bases, determined from the air temperature, were generally 200-300 m at Cape Blanco. In most of the supercritical areas, near the more southerly points, the inversion base height was generally in the 100-200-m range but increased farther offshore. The basic 100-200-m inversion base height zone broadens along the coast in more southerly areas.

The mean layer wind speeds increase from 12 to $20 \mathrm{~m} \mathrm{~s}^{-1}$ along Cape Blanco. Along Cape Mendocino, the upstream winds are $16 \mathrm{~m} \mathrm{~s}^{-1}$ and end up near $22 \mathrm{~m} \mathrm{~s}^{-1}$ downstream. The inbound winds at Point Sur start at $20 \mathrm{~m} \mathrm{~s}^{-1}$, decrease to $14 \mathrm{~m} \mathrm{~s}^{-1}$, and then accelerate to $20 \mathrm{~m} \mathrm{~s}^{-1}$ before changing again. In con- 
trast, the wind speeds tend to be much weaker off Point Conception, in the range of $8-12 \mathrm{~m} \mathrm{~s}^{-1}$.

\section{e. Expansion fan}

Expansion fans were found in the lee of Cape Mendocino and Point Sur, the two major capes that were sampled in detail. The 17 June flight around Point Sur is shown as an example (Fig. 13). The southbound marine layer is capped by an air temperature inversion that is at $250 \mathrm{~m}$ on the north end, dips below $200 \mathrm{~m}$ at the center, and then rises up to $300 \mathrm{~m}$ to the south end. Just above the marine layer, near $400 \mathrm{~m}$, there are two minimums centered about the single maximum temperature near $60 \mathrm{~km}$.

The wind direction is from the north-northwest to northwest. Wind speed maxima are centered at the top of the marine layer, near 200-m elevation on the north end and rising to $300 \mathrm{~m}$ at the south end, with a grand maximum of $25 \mathrm{~m} \mathrm{~s}^{-1}$ at $60 \mathrm{~km}$ (Fig. 14). On the north end, the inbound surface winds are supercritical at $12 \mathrm{~m} \mathrm{~s}^{-1}$, weaken to $6 \mathrm{~m} \mathrm{~s}^{-1}$ in a hydraulic jump, accelerate to a maximum of $19 \mathrm{~m} \mathrm{~s}^{-1}$ at $60 \mathrm{~km}$, and then decelerate to $14 \mathrm{~m} \mathrm{~s}^{-1}$ at the southern end. The acceleration and thinning of the layer seems to conform to a classic expansion

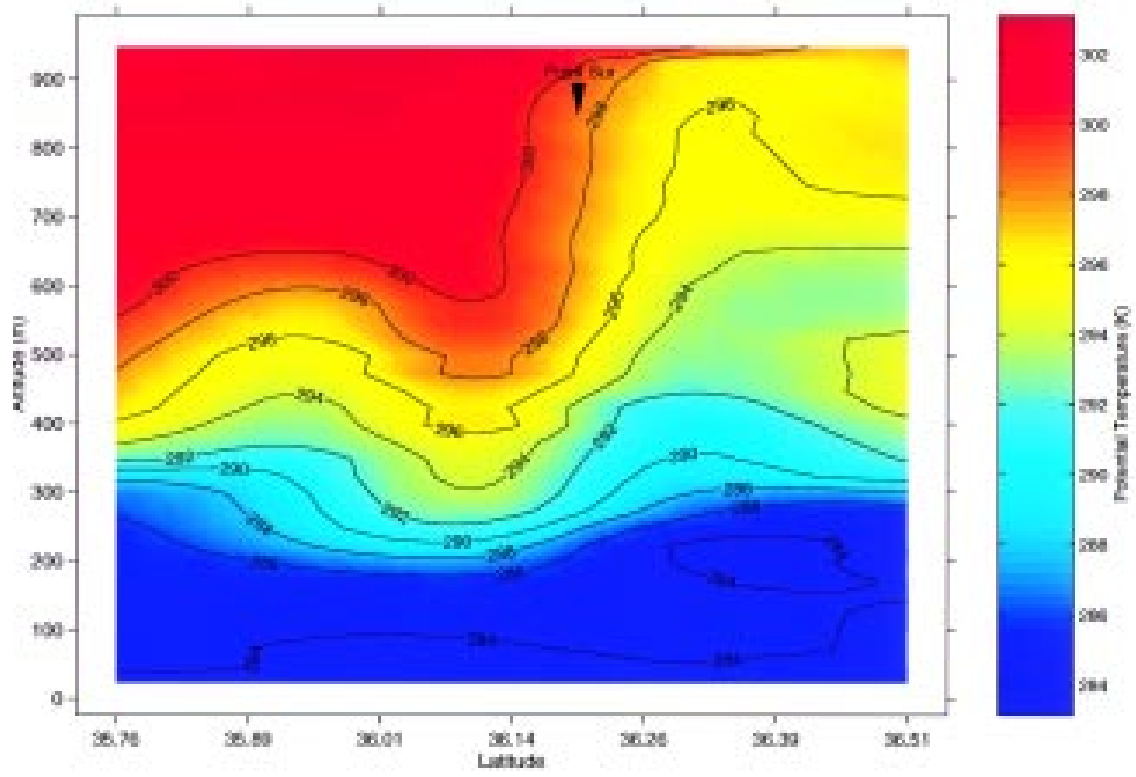

FIG. 13. Potential temperature cross sections along coast at Point Sur on 17 June.

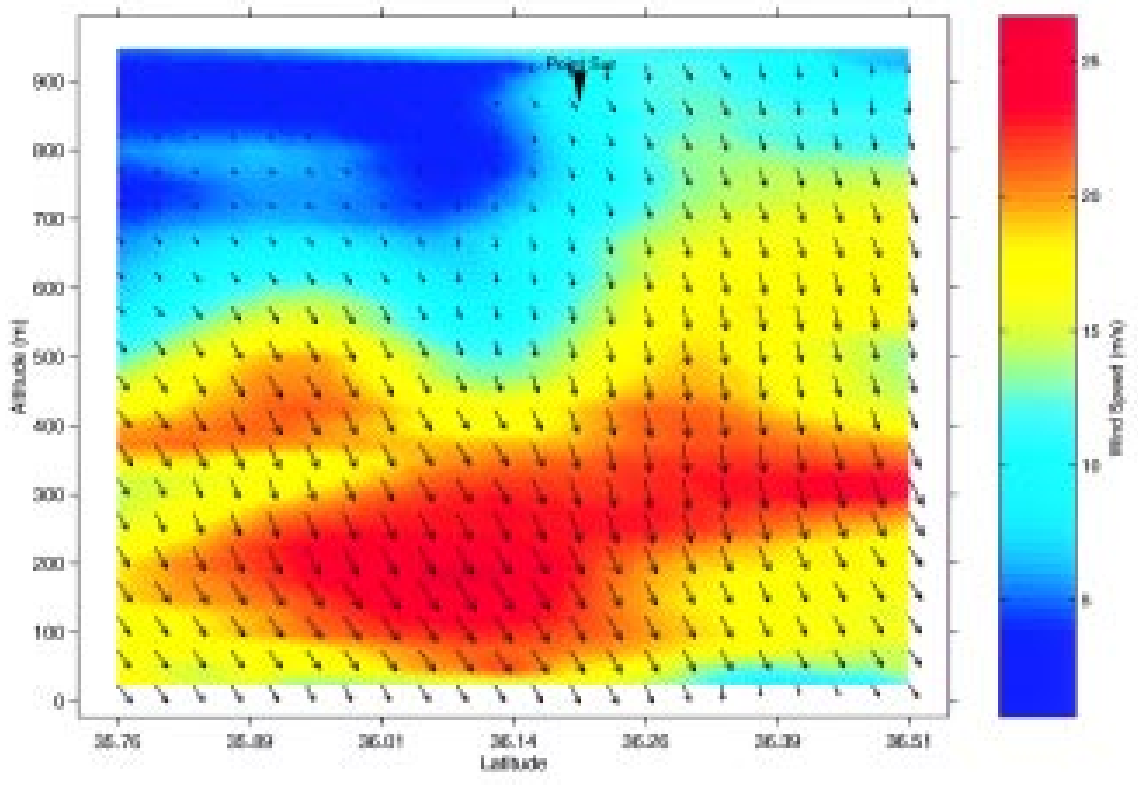

FIG. 14. As in Fig. 13 except for wind speed cross sections. fan.

A second, lesser maximum speed is above the marine layer at the north end at 400-m elevation. This may be an elevated expansion fan in the air temperature inversion that is a result of the flow at this level impinging on the topography between Monterey and Point Sur.

\section{f. Trapped events}

The 1994 Piper Seneca flights and other observations collected as part of the ECTD provided the first in situ observations of the structure of a propagating, coastally trapped wind reversal (often referred to as a "southerly surge"). The 10-11 June 1994 event was observed to have an overall wavelike character with an internal surface boundary layer imbedded within it. The event was not a simple two-layer wavelike disturbance, nor was it a two-layer gravity current (see Bane 1997; Ralph et al. 1995; Ralph et al. 1998). In fact, the detailed structure of this event showed that the marine boundary layer depth was essentially con- 
stant through the disturbance and that the wavelike disturbance occurred within the stratified layer capping the marine boundary layer (Ralph et al. 1998). A surface cloud layer (i.e., a fog layer) formed within the surface internal boundary layer below the wavelike disturbance in the inversion and these clouds progressed northward with the southerly wind induced near the surface (Dorman et al. 1998).

Other important results from the study of the 1011 June 1994 event reflect upon the synoptic forcing and mesoscale structure of this disturbance. The largerscale structure and its evolution were found to be similar to that identified by Mass and Bond (1996), where lee troughing associated with low-level offshore flow over northern California was hypothesized as the cause of a coastal pressure gradient reversal that forces the wind reversal. However, diagnosis of the 10-11 June 1994 event showed that the pressure gradient reversal was largely associated with the localized advection of warm air across the coastal mountains (Ralph et al. 1998). The mesoscale pressure distribution near the coast was also found to be consistent with the wavelike character of the disturbance in the detailed structure of the marine layer and inversion. A wedge of high pressure along the coast corresponded with the southerly winds consistent with a geostrophic Kelvin wave response.

During the 1996 ECTD, five southerly wind episodes were captured. Three of these episodes had a southerly surge component, one event produced weak southerlies above the surface (60-m level at Point Sur) without southerlies at the surface, and the final event was a transition to synoptic-scale southerlies without a surge component. One of the 1996 surge events occurred between Point Conception and Point Reyes (June 1996) and two surges occurred between Point Reyes and Cape Blanco (July and September 1996). The sections of coastline along which the June 1996 and June 1994 events occurred were primarily to the south of Point Reyes ("southern cases"), although the duration and intensity of the surface wind reversals were quite different. The July and September 1996 events occurred along nearly identical sections of the coast north of Point Reyes ("northern cases") and had similar duration and intensities to the surface wind reversals. Temperature and velocity sections from the Seneca for these surges suggest that each had a southerly flow leading edge above a constant depth, marine boundary layer. This supports the notion that a complex vertical structure that involves a disturbance in the inversion layer, similar to that observed in June
1994, is the typical situation as opposed to an isolated occurrence.

Similarities exist between the structure of the June 1994 surge and the June 1996 surge, measured during CW96. Both of these events propagated through the Point Conception to Point Reyes region. Vertical sections of potential temperature and alongshore velocity through these events show that the leading edge of the southerly wind flow was about $400 \mathrm{~m}$ above the surface, overlying northerly flow in each instance (Fig. 15). The general wavelike character of the inversion topography (i.e., elevated inversion top to the south) is also apparent in each case. Differences include the fact that the southerlies jet is more centered in the inversion in the 1994 case, while in the 1996 case the jet is at the transition between the mixed layer and the inversion.

Some of the most striking differences between the June 1994 and June 1996 cases occurred on the synoptic scale. The June 1994 case was characterized by a well-defined upper-level ridge along the coast with pronounced offshore flow at $850 \mathrm{mb}$ (see Ralph et al. 1998), similar to the synoptic composites of Mass and Bond (1996). The June 1996 event had a very weak upper-level ridge (although very high 500-mb heights) and virtually no offshore flow at $850 \mathrm{mb}$ in synoptic analyses from the National Centers for Environmental Prediction Eta Model. Wind profiler observations from Fort Ord near Monterey (the only common profiler site for the two events) show a pronounced 300-m-deep marine layer with weak offshore flow above the inversion prior to the June 1996 event. In contrast, the June 1994 event lacked an identifiable marine layer and showed strong (10-12.5 $\left.\mathrm{m} \mathrm{s}^{-1}\right)$ offshore flow for the Monterey Bay region prior to the event. These differences may reflect upon the weaker and more short-lived nature of the June 1996 event, but they also indicate that even rather modest forcing can trigger a southerly surge. There are additional similarities as well as distinct differences between these two southern cases and the two northern cases observed during 1996. As stated earlier, a more in-depth discussion of the observations of these southerly surge cases and insights gained in idealized and full-physics model studies will be presented in a later article in the Bulletin of the American Meteorological Society.

\section{Application of numerical models}

An important part of the analysis and understanding of the coastal boundary is the application of vari- 

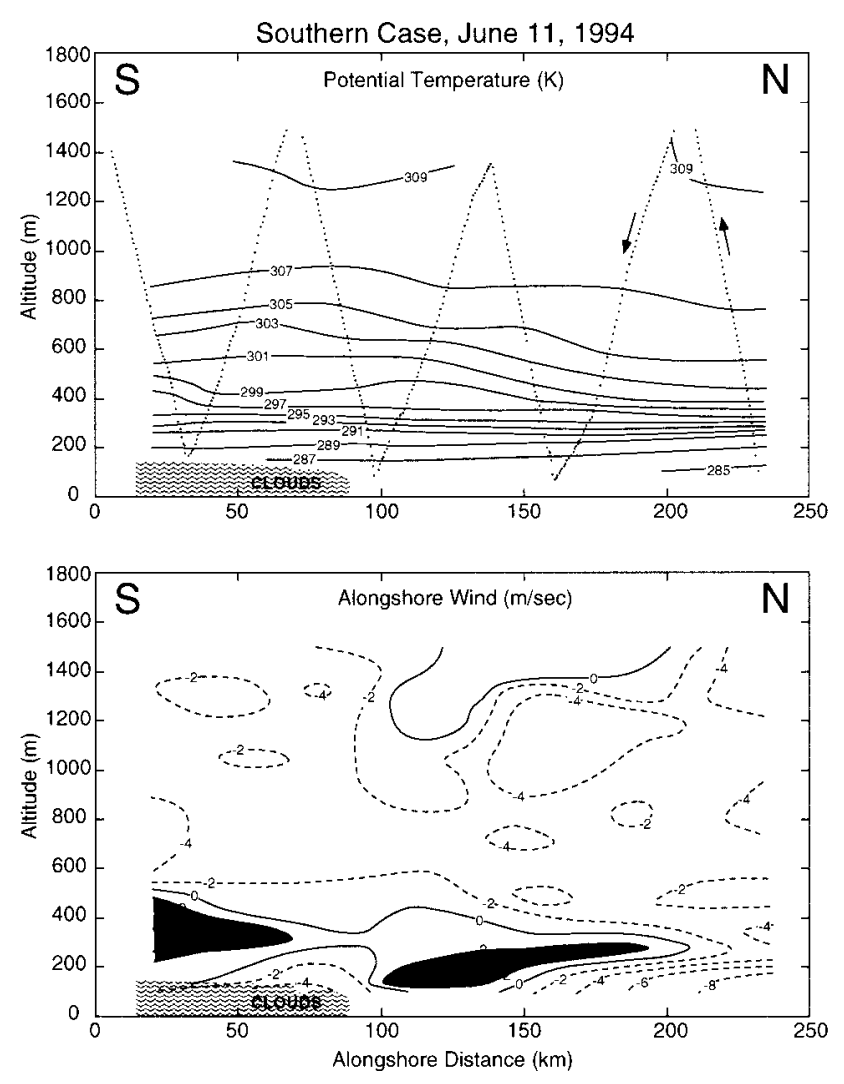

FIG. 15. Potential temperature and wind velocity cross sections for June 1994, obtained by UNC Piper Seneca.

ous numerical models. COAMPS (Hodur 1997) and the MIUU mesoscale model (Tjernström et al. 1988; Enger 1990) are the focus of the ongoing simulations. COAMPS, which is described above, was used as the primary mesoscale forecast tool for CW96. It has the advantage of assimilating large-scale observed fields to provide complete boundary conditions for the analysis.

\section{a. Application of COAMPS}

\section{1) EXPANSION FAN}

COAMPS forecasts for 17 June 1996 compared favorably with the aircraft observations, showing abrupt shallowing of the boundary layer and strong acceleration in the lee of Point Sur. Both the observations and the model showed many characteristics of an expansion fan. Detailed examination of the model output indicated that other processes might be active as well. Shown in Fig. 16 is a family of 18-h back trajectories from the model terminating at the location of the maximum low-level wind speed at several different elevations. The lowest trajectory (ending at $35 \mathrm{~m}$ ) shows flow along the coast turning around Point Sur, much as would be expected for an expansion fan.

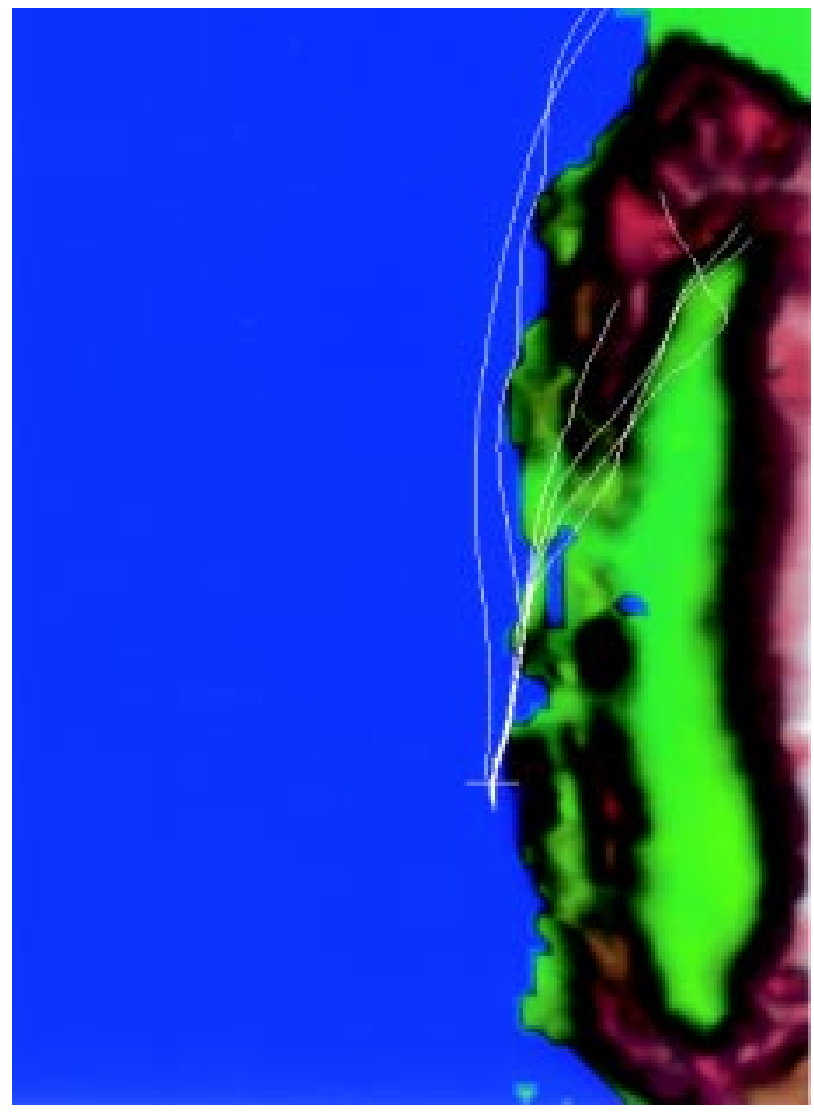

FIG. 16. The 18-h back trajectories for 17 June.

However, all of the model trajectories at higher levels show large displacements due to flow over topography. On the other hand, aircraft measurements over water show only coast-parallel flow as though the air mass came around the topography, suggesting that lee flow is very limited in over water affects.

\section{2) LOW-LEVEL JET}

The COAMPS model forecasts were compared with the detailed marine layer structure observed along the flight paths near Cape Mendocino on 12 June. The observations north of the cape show the MBL to be $\sim 500 \mathrm{~m}$ deep near the coast, deepening to $\sim 600 \mathrm{~m}$ at the western end of the flight track. A LLJ having a wind speed maximum in excess of $20 \mathrm{~m} \mathrm{~s}^{-1}$ lies at the base of the temperature inversion along the central portion of this flight track. The COAMPS 21-h forecast (not shown) valid at the flight time shows these same general characteristics; however, its MBL depth ( 300 m near the coast) is too shallow and its LLJ maximum $\left(\sim 31 \mathrm{~m} \mathrm{~s}^{-1}\right)$ is too strong.

The aircraft observations show that the flow accelerates, and the MBL lowers upon passing Cape 


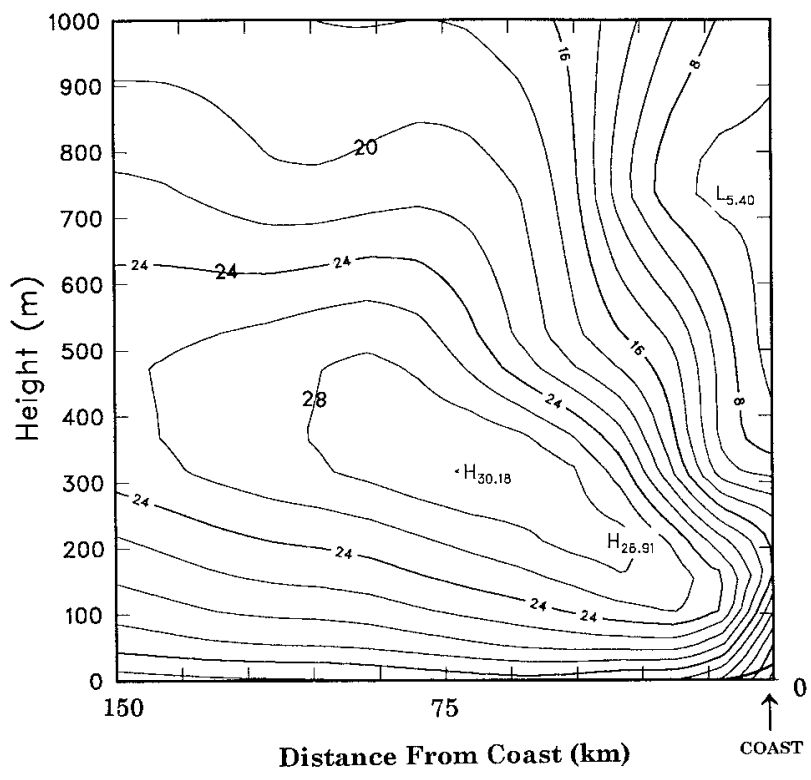

FIG. 17. Modeled cross section from COAMPS corresponding to Figs. $8 \mathrm{c}, \mathrm{d}$.

Mendocino. The southernmost cross section (Fig. 8c) indicates that the marine layer is only $\sim 250 \mathrm{~m}$ deep near the coast but deepens to $\sim 700 \mathrm{~m}$ at the western end of the track. The LLJ along this cross section fol-

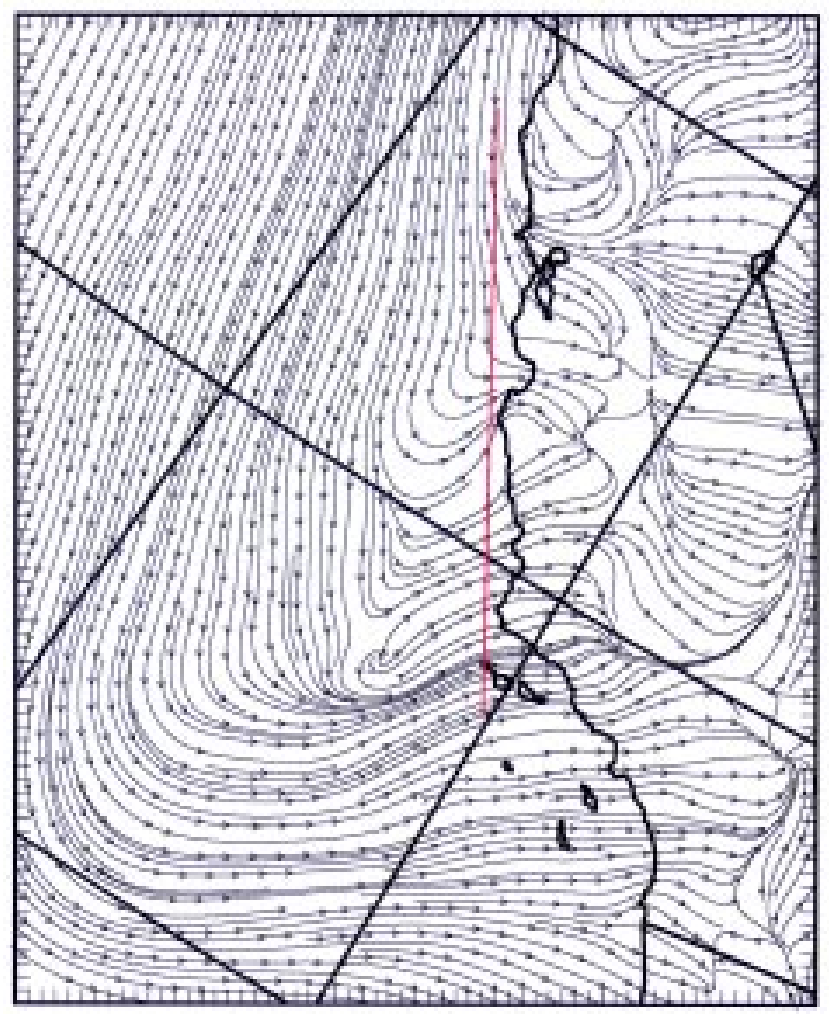

FIG. 18. 24-h COAMPS forecast wind vectors at 1000-mb level, valid at 0000 UTC 11 June 1994. lows the inversion, sloping strongly downward toward the coast (Fig. 8d), and has a maximum value in excess of $25 \mathrm{~m} \mathrm{~s}^{-1}$ at a height of $\sim 350 \mathrm{~m}$. The COAMPS 24-h forecast (valid at the time of the flight) along this same track is in fair agreement with the observations, showing a 200 -m-deep MBL near the coast deepening to $\sim 400 \mathrm{~m}$ to the west. The COAMPS forecast LLJ also slopes along the inversion and has a maximum of $\sim 30 \mathrm{~m} \mathrm{~s}^{-1}$ (Fig. 17).

The model's bias toward a shallow marine layer has a strong influence upon its bias toward a stronger LLJ. Much of the LLJ intensity derives from the integrated effect of the baroclinity above the marine layer upon the thermal wind. With a sloping boundary layer that is shallower than it should be, the integrated thermal wind is stronger than it ought to be. Thus, a bias in boundary layer depth is strongly correlated with a bias in LLJ strength.

The COAMPS model shows flow convergence on the upwind side of Cape Mendocino due to partial blocking and divergence in the lee. In addition, 3D trajectory analysis indicates there is considerable flow over the cape, with descent and acceleration on the lee side. The abrupt change in marine layer depth and small-scale variations in the LLJ flow rounding the cape are suggestive of supercritical expansion fan behavior. Further modeling and analysis are required to obtain a more complete understanding of the complex interplay of dynamics at work.

\section{3) TRAPPED EVENTS}

A COAMPS simulation of the 10-11 June 1994 event shows many of the features described in section $4 \mathrm{f}$, including the complex, multilayered vertical structure; the disturbance in the stratified layer overlaying the marine boundary layer; and the "tongue" of low clouds/fog progressing northward along the coast. Thompson et al. (1997) describe these simulation and sensitivity studies.

Shown in Fig. 18 are 24-h forecast model wind vectors at the 1000-mb level valid at 0000 UTC 11 June 1994. Note the strong southerly flow along the coast and into Monterey Bay at this time. Figure 19 shows cross sections (the plane is indicated in Fig. 18) valid at 1200 UTC 10 June 1994. Figure 19a is from the control simulation, while Fig. 19b is from a simulation in which the coastline is simplified to remove bays and points along the coast and a uniform 840-mhigh ridge is placed along the straight coastline from Point Conception to Point Reyes. In both cross sections, note the leading edge of a disturbance in the 
(a)

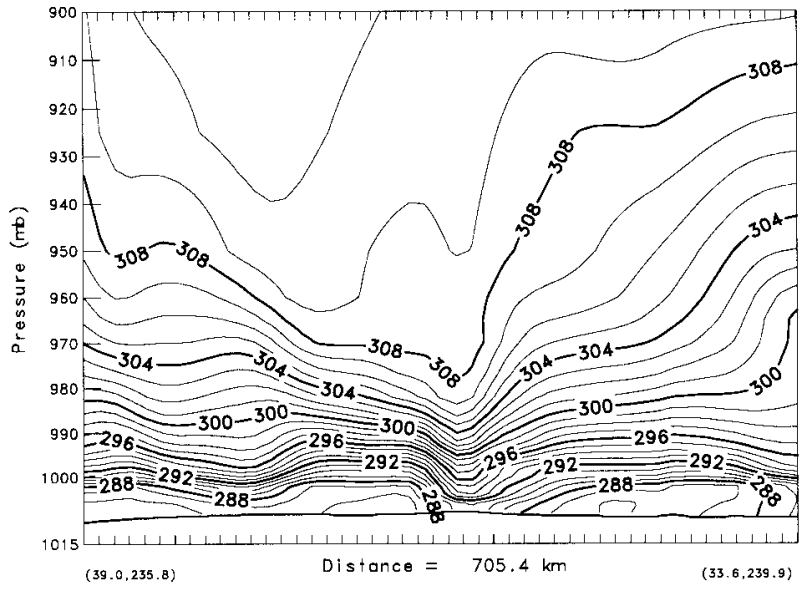

(b)

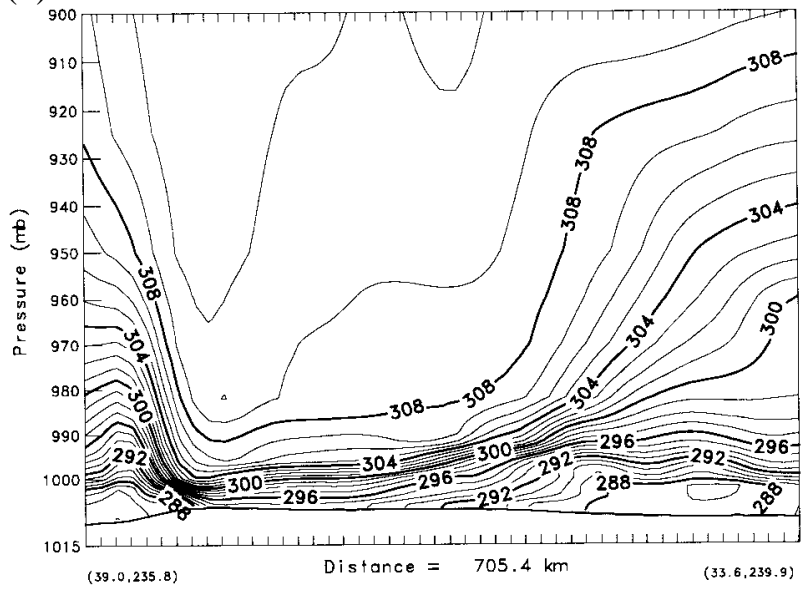

Fig. 19. Cross sections of potential temperature, corresponding to Fig. 18 for (a) a control simulation and (b) a simulation using a simplified coastline. North is to the left of the figure. The boundary layer is suppressed toward the north in both cases.

stable layer above the boundary layer, the strongly suppressed boundary layer to the north, and the deeper, cooler boundary layer to the south. This cooler, deeper boundary layer propagates to the north along the coast. In Fig. 19b, flow over the fictitious ridge results in a more strongly suppressed boundary layer and a more uniform vertical structure in the leading edge of the disturbance. In this simulation, the largest decrease in pressure is coincident with the region in which the boundary layer is most strongly suppressed, indicating that warm advection from the elevated heat source (i.e., the fictitious terrain) is important in forcing the mesoscale pressure gradient.

COAMPS simulations have also been performed for the June, July, and September 1996 cases.

\section{b. Application of MIUU model}

The MIUU model is used to investigate specific observed cases. The model fields can expand and generalize the observations and address more completely turbulence budgets (e.g., Cui et al. 1998). Parameter sensitivity studies are performed using realistic but relatively simple initial conditions to force the model (Grisogono and Tjernström 1996; Tjernström and Grisogono 1996).

The MIUU model is hydrostatic, with a terraininfluenced vertical coordinate and telescopic grids facilitating high-resolution PBL studies in the interior domain of the model. Typical horizontal resolution in the model center is $\mathrm{O}(1) \mathrm{km}$, while the vertical resolution varies from a few meters close to the surface to $\sim 250 \mathrm{~m}$ at the model top. The model domain is typically several hundred kilometers horizontally and 5-
$10 \mathrm{~km}$ vertically. Particular attention is paid to the turbulence closure, which is based on the so-called level 2.5 scheme developed by Yamada and Mellor (1979). This scheme was modified by Andren (1990) to improve the near-wall layer behavior and ensure realizability. It is a compromise between numerical efficiency and a realistic treatment of turbulence, and it makes it possible to compute accurate second-order moments while retaining numerical efficiency for 3D model applications. The model includes routines for subgrid-scale condensation and radiation as well as surface energy balance.

\section{LOW-LEVEL JET}

The boundary layer observed on 7 June 1996 (Figs. 8a,b) is simulated. Model fields, which correspond to the observed wind speed and temperature cross sections, are shown in Fig. 20. While the model boundary layer is $\sim 100 \mathrm{~m}$ too shallow, the position and wind speed in the jet agrees with the observations. The overall structure of the model boundary layer is also in good agreement with the measurements, for example, the slope of the marine layer top, the jet axis, and the collapse of the boundary layer into Shelter Cove. Model deficiencies include a somewhat too shallow PBL (by 50-150 m) and too small horizontal gradients in the wind speed; that is, the horizontal contrasts along the coast are somewhat smaller in the model than in the measurements.

In Fig. 21, the wind stress field and the curl of the stress vector are shown. The stress vectors are aligned with the wind vector, which is an inherent property in the model closure, while the magnitude is given 
June 07, 1996, Wind and temperature section, Shelter Cowe
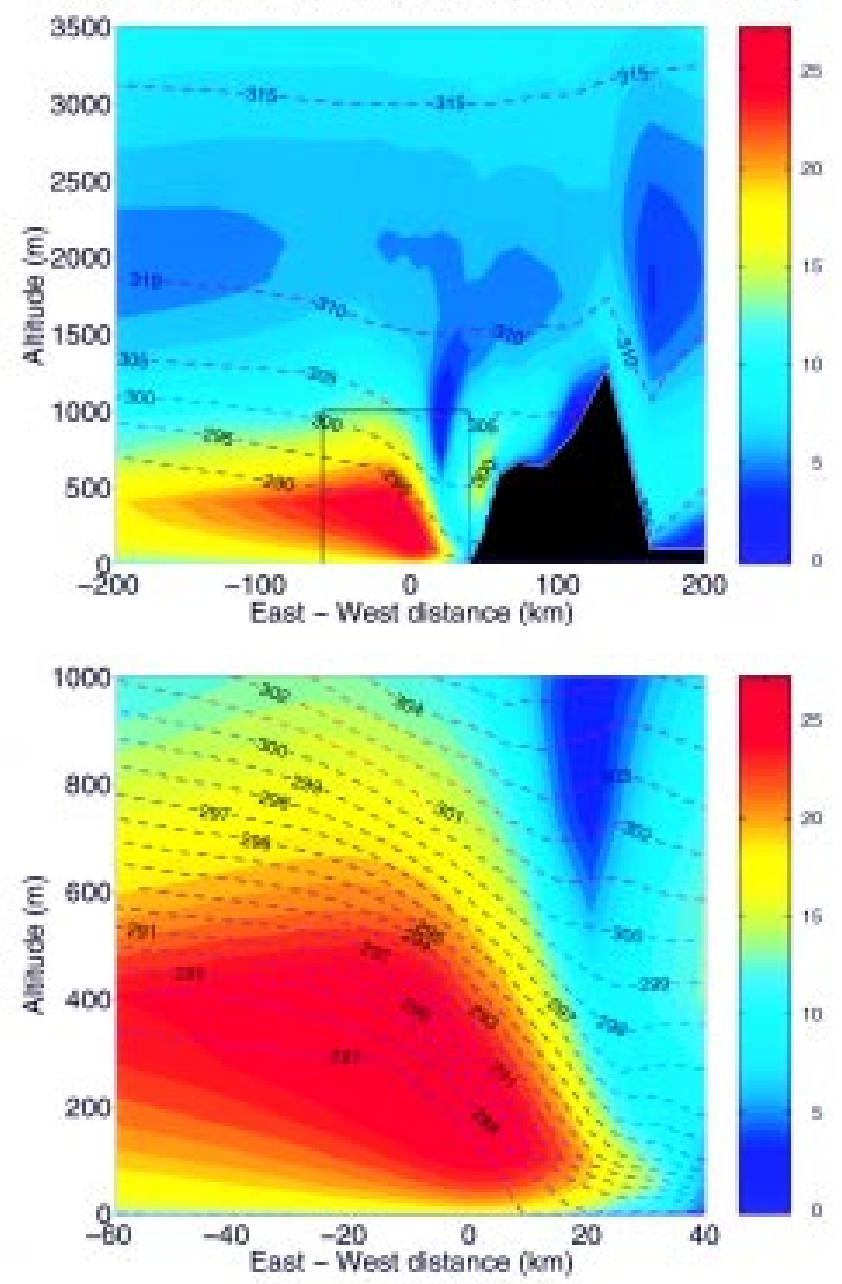

FIG. 20. Model cross section corresponding to Figs. 8a,b, showing wind speed in colors and isolines of potential temperature (red above and blue at and below $300 \mathrm{~K}$ ). The upper panel shows a larger area, with the measurements area inserted as a black box. Lower panel shows the measurements area in more detail.

by the friction velocity calculated from the closure. Taking the curl of this vector indicates upwellingfavorable conditions along the coast around the cape, intensifying in a large area south of the cape and into Shelter Cove, inshore of the wind speed maximum. The maximum upwelling is found at the southwest point of the cape while the offshore values, west of $\mathrm{x} \sim 0 \mathrm{~km}$, are close to zero. This distribution agrees qualitatively with the SST observations from the C130 measurements.

Model momentum budget calculations (not shown) indicate that the upstream flow is generally in semigeostrophic balance. Inshore of $\sim 50 \mathrm{~km}$ from the local coast, advection is important, which is probably
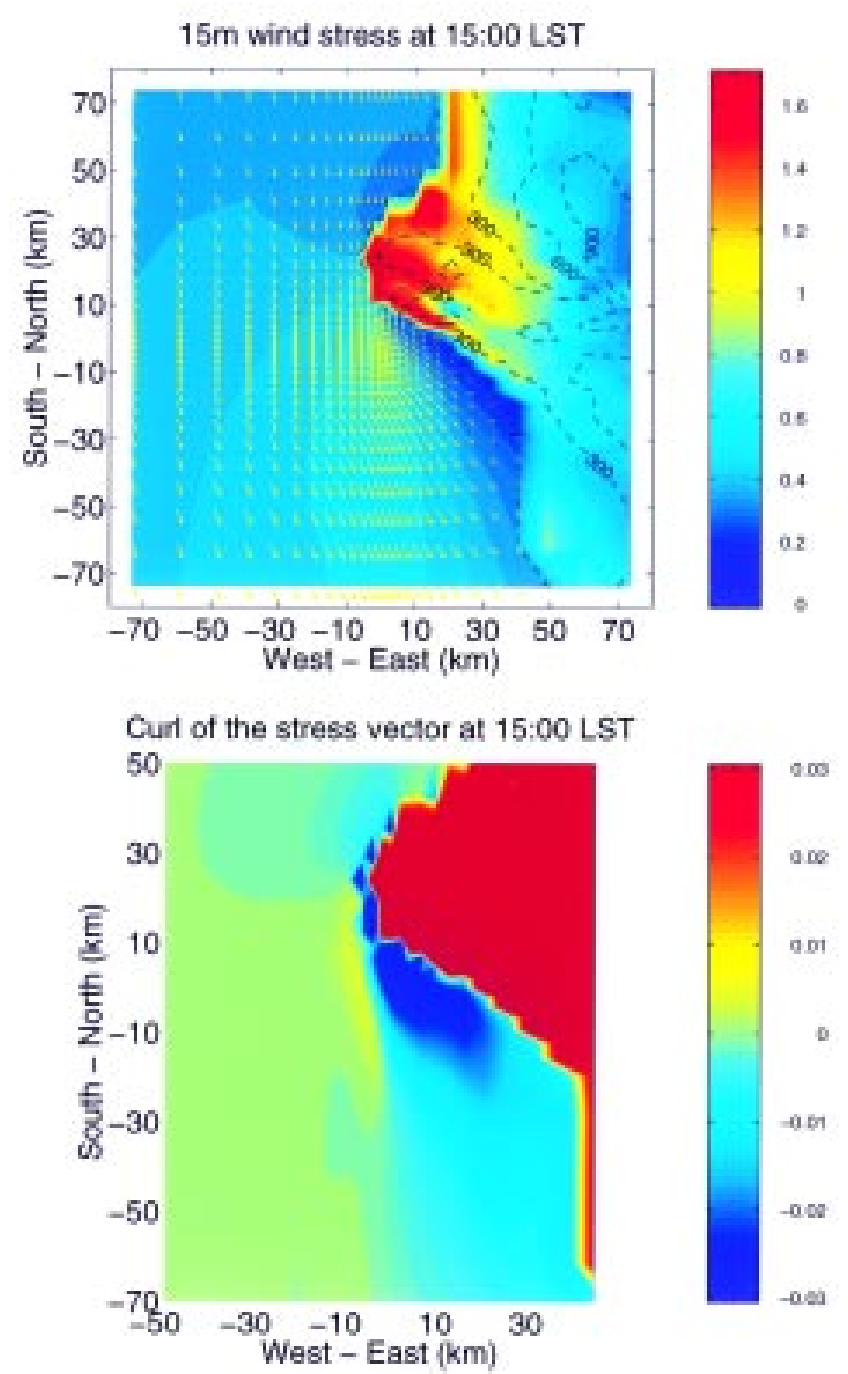

FIG. 21. Wind stress vectors and friction velocity $\left(\mathrm{m}^{2} \mathrm{~s}^{-1}\right.$, upper panel) and the magnitude of the vertical component of the curl of the stress vector ( $\mathrm{m} \mathrm{s}^{-2}$, lower panel). The stress vector is defined positive along the mean wind vector and negative values of the curl indicate upwelling-favorable conditions.

due to the curvature of the coast around the cape. At and downstream of Cape Mendocino the flow is generally ageostrophic in both components, although the flow seems to approach semigeostrophic balance again farther south.

Froude numbers, computed from the model inversion height, the average wind speed of the layer, and the capping inversion strength, for 17 June near Point Sur, are shown in Fig. 22. The marine layer slopes down toward the coastline, having the strongest gradient a couple of kilometers down the coast from the point. The flow is essentially supercritical everywhere with relatively largest Froude numbers near the coast, which compares well with the observations. 


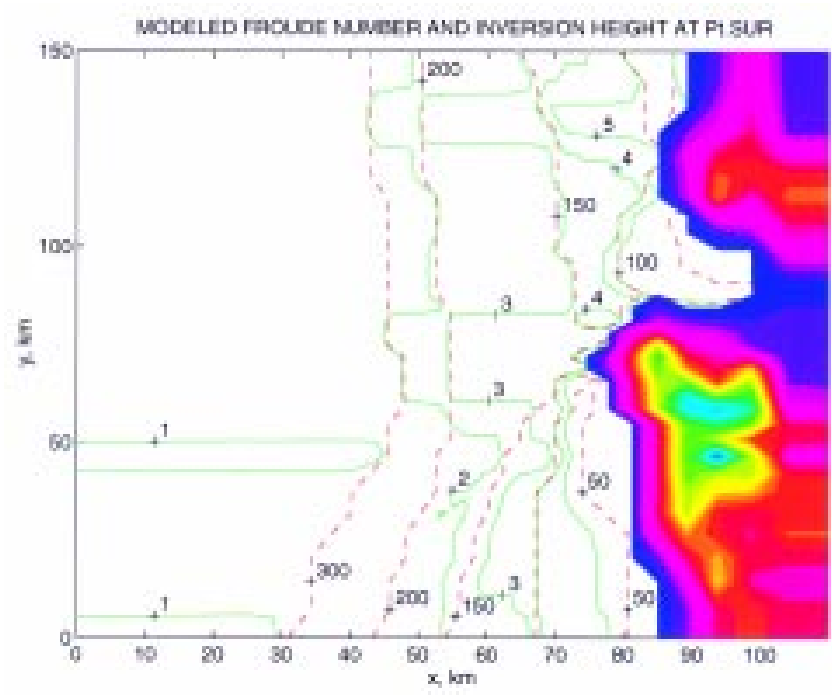

FIG. 22. Froude number (green, solid) and marine inversion height (red, dashed) as derived from the MIUU model output for 1800 GMT on 17 June.

\section{Summary}

A few of the highlights of the Coastal Waves 1996 experiment have been presented. Some of the most comprehensive measurements of the topographically forced marine layer have been collected. We were particularly fortunate with the application of SABL, in addition to high-resolution in situ observations. This instrument will contribute much to improving our understanding of the connection between physical processes and the structure of the marine layer. It has become an almost essential tool for studies of boundary layer development. We have captured details of many of the topographic events that occur along the California coast. Measurements were obtained sufficiently far offshore to distinguish between coastal modification and open ocean conditions. The COAMPS model proved to be an excellent mesoscale forecast tool, which contributed to the success of the field experiment. Both the COAMPS and MIUU models are integral parts of the ongoing analysis.

The coastal marine boundary layer is a relatively poorly understood environment. Measurements are typically limited to shore stations and a few surface meteorological measurements from buoys. Our results have highlighted the large spatial variability that occurs directly in response to topographic effects. The routine measurements are not sufficient to resolve this variability. Numerical weather prediction model boundary conditions cannot properly define the forecast system and often underestimate the wind speed and surface wave conditions in the nearshore region.

Acknowledgments. This work was supported by the National Science Foundation Division of Atmospheric Sciences, the Office of Naval Research, the Naval Research Laboratory, and the National Oceanographic and Atmospheric Administration. We would especially like to thank the crew of the NCAR C-130 Hercules aircraft. DR and CD would like to thank Michele Petrie for her help in the collection and analysis of these data. JB would like to thank Sara Haines for her invaluable help with the collection and analysis of the UNC aircraft data and Meredith Sessions for copiloting all of the 1996 research flights.

\section{References}

Andren, A., 1990: Evaluation of a turbulence closure scheme suitable for air-pollution applications. J. Appl. Meteor., 29, 224-239.

Bane, J. M., 1997: Rapid-response aircraft surveys of short-lived events in the coastal atmosphere. Proc. The Rapid Env. Assessment Conf., SACLANT Undersea Research Center Tech. Rep., 11-14.

— S. M. Haines, L. Armi, and M. H. Sessions, 1995: The California coastal marine layer: Winds and thermodynamics, technical report, June 1994 aircraft measurement program. University of North Carolina Rep. CMS-95-1, 289 pp. [Available from University of North Carolina, Marine Sciences Department, Chapel Hill, NC 27599-3300.]

Beardsley, R. C., C. E. Dorman, C. A. Friehe, L. K. Rosenfeld, and C. D. Winant, 1987: Local atmospheric forcing during the Coastal Ocean Dynamics Experiment. 1. A description of the marine boundary layer and atmospheric conditions over a northern California upwelling region. J. Geophys. Res., 92, 1467-1488.

Bond, N. A., C. F. Mass, and J. E. Overland, 1996: Coastally trapped wind reversals along the United States west coast during the warm season. Part I: Climatology and temporal evolution. Mon. Wea. Rev., 124, 430-445.

Brooks, I. M., and D. P. Rogers, 1997: Aircraft observations of boundary layer rolls off the coast of California. J. Atmos. Sci., 54, 1834-1849.

Burk, S. D., and W. T. Thompson, 1996: The summertime lowlevel jet and marine boundary layer structure along the California coast. Mon. Wea. Rev., 124, 668-686.

Cui, Z., M. Tjernström, and B. Grisogono, 1998: Idealized simulations of atmospheric coastal flow along the central coast of California. J. Appl. Meteor., in press.

Dorman, C. E., 1985: Evidence of Kelvin waves in California's marine layer and related eddy generation. Mon. Wea. Rev., 113, 827-839.

— 1987: Possible role of gravity currents in northern California's coastal summer wind reversals. J. Geophys. Res., 92, 1497-1506.

— sphere along the west coast of the United States, 1981-1990. J. Geophys. Res., 100, 16 029-16 044. 
— L. L. Armi, J. M. Bane, and D. Rogers. 1998: Sea surface mixed layer during the 10-11 June 1994, California coastally trapped event. Mon. Wea. Rev., 126, 600-619.

Enger, L., 1990: Simulation of dispersion in moderately complex terrain-Part A. The fluid dynamic model. Atmos. Environ., 24A, 2431-2446.

Fairall, C., E. F. Bradley, D. P. Rogers, J. B. Edson, and G. S. Young, 1996: Bulk parameterization of air-sea fluxes for the Tropical Ocean Global Atmosphere Coupled Ocean-Atmosphere Response Experiment. J. Geophys. Res., 101, 3747-3764.

Grisogono, B., and M. Tjernström, 1996: Thermal mesoscale circulations on the Baltic coast. 2. Perturbation of surface parameters. J. Geophys. Res., 101, 18 999-19 012.

Harshvardhan, R. Davies, D. Randall, and T. Corsetti, 1987: A fast radiation parameterization for atmospheric circulation models. J. Geophys. Res., 92, 1009-1015.

Hodur, R. M., 1997: The Naval Research Laboratory's Coupled Ocean/Atmosphere Mesoscale Prediction System (COAMPS). Mon. Wea. Rev., 125, 1414-1430.

Holtslag, A. A. M., and F. T. M. Nieuwstadt, 1986: Scaling the atmospheric boundary layer. Bound.-Layer Meteor., 36, 201-209.

Hsu, S. A., 1983: On the growth of a thermally modified boundary layer by advection of warm air over a cooler sea. $J$. Geophys. Res., 88, 771-774.

Kain, J. S., and J. M. Fritsch, 1993: Convective parameterization for mesoscale models: The Kain-Fritsch scheme. The Representation of Cumulus Convection in Numerical Models, Meteor. Monogr., No. 46, Amer. Meteor. Soc., 165-170.

Klemp, J., and R. Wilhelmson, 1978: The simulation of three-dimensional convective storm dynamics. J. Atmos. Sci., 35, 1070-1096.

Louis, J. F., M. Tiedtke, and J. F. Geleyn, 1982: A short history of the operational PBL-parameterization at ECMWF. Workshop on Planetary Boundary Parameterization, Reading, United Kingdom, ECMWF, 59-79.

Mass, C. F., and N. A. Bond, 1996: Coastally trapped wind reversals along the United States west coast during the warm season. Part II: Synoptic evolution. Mon. Wea. Rev., 124, 446-461.

Mellor, G. L., and T. Yamada, 1982: Development of a turbulence closure for geophysical fluid problems. Rev. Geophys. Space Phys., 20, 851-875.

Neiburger, M., D. S. Johnson, and C. W. Chien, 1961: Studies of the structure of the atmosphere over the eastern Pacific Ocean in the summer. The Inversion Over the Eastern North Pacific Ocean, University of California Press, 1-94.

Nelson, C. S., 1977: Wind stress and wind stress curl over the California current. NMFS Rep. SSRF-714, 87 pp. [Available from Scientific Pub. Office, 7600 Sand Point Way, N.E., Bin C 15700, Seattle, WA 98115.]

Nieuwstadt, F. T. M., 1984: The turbulence structure of the stable, nocturnal boundary layer. J. Atmos. Sci., 41, 2202-2216.

Oncley, S. P., C. A. Friehe, J. C. LaRue, J. A. Businger, E. C. Itsweire, and S. S. Chang, 1996: Surface-layer fluxes, profiles and turbulence measurements over uniform terrain under near neutral conditions. J. Atmos. Sci., 53, 1029-1044.
Overland, J. E., 1984: Scale analysis of marine winds in straits and along mountainous coasts. Mon. Wea. Rev., 112, 2530 2534.

Ralph, F. M., P. J. Neiman, P. O. Persson, W. D. Neff, J. Miletta, L. Armi, and J. M. Bane, 1995: Observations of an orographically trapped disturbance along the California coast on 1011 June 1994. Preprints, Seventh Conf. on Mountain Meteorology, Breckenridge, CO, Amer. Meteor. Soc., 204-211.

—, L. Armi, J. M. Bane, C. Dorman, W. D. Neff, P. J. Nieman, W. Nuss, and P. O. G. Persson, 1998: Observations and analysis of the 10-11 June 1994 coastally trapped disturbance. Mon. Wea. Rev., in press.

Reason, C. J. C., 1989: Coastally trapped disturbances in the lower atmosphere. Ph.D. thesis, University of British Columbia, 214 pp.

— the lower atmosphere: Dynamic commonalities and geographic diversity. Prog. Phys. Geogr., 14, 178-198.

Rogers, D. P., D. W. Johnson, and C. A. Friehe, 1995a: The stable internal boundary layer over a coastal sea. Part I: Airborne measurements of the mean and turbulence structure. J. Atmos. Sci., 52, 667-683.

,-- , and ——, 1995b: The stable internal boundary layer over a coastal sea. Part II: Gravity waves and ageostrophic wind forcing. J. Atmos. Sci., 52, 684-696.

Rutledge, S. A., and P. V. Hobbs, 1983: The mesoscale and microscale structure of organization of clouds and precipitation in midlatitude cyclones. Part VIII: A model for the "seederfeeder" process in warm-frontal rainbands. J. Atmos. Sci., 40, 1185-1206.

Sorbjan, Z., 1986: On similarity in the atmospheric boundary layer. Bound.-Layer Meteor., 34, 377-397.

Thompson, W. T., T. Haack, J. D. Doyle, and S. D. Burk, 1997: A nonhydrostatic mesoscale simulation of the 10-11 June 1994 coastally trapped wind reversal. Mon. Wea. Rev., 125, 3211-3230.

Tjernström, M., and B. Grisogono, 1996: Thermal mesoscale circulations on the Baltic Coast. 1. A numerical case study. $J$. Geophys. Res., 101, 18 979-18 997.

_, L. Enger, and A. Adren, 1988: A three-dimensional numerical model for studies of atmospheric flows on the mesog-scale. J. Theor. Appl. Mech., 7 (special issue suppl. 2), 167194.

Winant, C. D., C. E. Dorman, C. A. Friehe, and R. C. Beardsley, 1988: The marine layer off northern California: An example of supercritical channel flow. J. Atmos. Sci., 45, 3588-3605.

Yamada, T., and G. Mellor, 1979: A numerical simulation of the BOMEX data using a turbulence closure model coupled with ensemble cloud relations. Quart. J. Roy. Meteor. Soc., 105, 915-944.

Zemba, J., and C. A. Friehe, 1987: The marine atmospheric boundary layer jet in the Coastal Ocean Dynamics Experiment. $J$. Geophys. Res., 92, 1489-1496. 